\title{
2016 ACC/AHA guideline focused update on duration of dual antiplatelet therapy in patients with coronary artery disease
}

\begin{abstract}
A report of the American College of Cardiology/American Heart Association Task Force on Clinical Practice
\end{abstract} Guidelines

An update of the 2011 ACCF/AHA/SCAI guideline for percutaneous coronary intervention, 2011 ACCF/AHA guideline for coronary artery bypass graft surgery, 2012 ACC/AHA/ACP/AATS/PCNA/SCAI/STS guideline for the diagnosis and management of patients with stable ischemic heart disease, $2013 \mathrm{ACCF} / \mathrm{AHA}$ guideline for the management of ST-elevation myocardial infarction, 2014 AHA/ACC guideline for the management of patients with non-ST-elevation acute coronary syndromes, and 2014 ACC/AHA guideline on perioperative cardiovascular evaluation and management of patients undergoing noncardiac surgery

Developed in collaboration with The American Association for Thoracic Surgery, American Society of Anesthesiologists, Society for Cardiovascular Angiography and Interventions, Society of Cardiovascular Anesthesiologists, and Society of Thoracic Surgeons.

Endorsed by Preventive Cardiovascular Nurses Association and Society for Vascular Surgery

Focused Glenn N. Levine, MD, FACC, FAHA, Chair, $†$ Eric R. Bates, MD, FACC, FAHA, FSCAI,*, Update Writing Group*: John A. Bittl, MD, FACC, $\S$ Ralph G. Brindis, MD, MPH, MACC, FAHA, Stephan D. Fihn, MD, MPH, $₫$ Lee A. Fleisher, MD, FACC, FAHA, Christopher B. Granger, MD, FACC, FAHA,$* \ngtr$ Richard A. Lange, MD, MBA, FACC, $\ddagger$ Michael J. Mack, MD, FACC, ${ }^{*}$, Laura Mauri, MD, MSc, FACC, FAHA, FSCAI, ${ }^{*}+$ Roxana Mehran, MD, FACC, FAHA, FSCAI, ${ }^{*} \#$ Debabrata Mukherjee, MD, FACC, FAHA, FSCAI,$\ddagger$ L. Kristin Newby, MD, MHS, FACC, FAHA, ${ }^{*}+$

Patrick T. O’Gara, MD, FACC, FAHA, $₫$ Marc S. Sabatine, MD, MPH, FACC, FAHA, ${ }^{*} \dagger$ Peter K. Smith, MD, FACC, $\ddagger$ and Sidney C. Smith, Jr, MD, FACC, FAHA
ACC/AHA
Jonathan L. Halperin, MD, FACC, FAHA, Chair,
Task Force Glenn N. Levine, MD, FACC, FAHA, Chair-Elect, Sana M. Al-Khatib, MD, MHS, FACC, Members: FAHA, Kim K. Birtcher, PharmD, MS, AACC, Biykem Bozkurt, MD, PhD, FACC, FAHA, Ralph G. Brindis, MD, MPH, MACC, FAHA, Joaquin E. Cigarroa, MD, FACC, Lesley H. Curtis, PhD, FAHA, Lee A. Fleisher, MD, FACC, FAHA,

\footnotetext{
* Focused Update writing group members are required to recuse themselves from voting on sections to which their specific relationships with industry may apply; see Appendix 1 for detailed information. ${ }^{\dagger}$ ACC/AHATask Force on Clinical Practice Guidelines Liaison. ${ }^{\ddagger}$ ACC/AHA Representative. ${ }^{\S}$ Evidence Review Committee Chair. "American Society of Anesthesiologists/Society of Cardiovascular Anesthesiologists Representative. "American Association for Thoracic Surgery/Society of Thoracic Surgeons Representative. ${ }^{\#}$ Society for Cardiovascular Angiography and Interventions Representative.

This document was approved by the American College of Cardiology Board of Trustees and the American Heart Association Science Advisory and Coordinating Committee in February 2016, and the American Heart Association Executive Committee in March 2016.

The Comprehensive RWI Data Supplement table is available with this article at http://circ.ahajournals.org/lookup/suppl/doi:10.1161/CIR.0000000000000404/-/ DC1.

The Data Supplement is available with this article at http://circ.ahajournals.org/ lookup/suppl/doi:10.1161/CIR.0000000000000404/-/DC2.

The American Heart Association requests that this document be cited as follows: Levine GN, Bates ER, Bittl JA, Brindis RG, Fihn SD, Fleisher LA, Granger CB, Lange RA, Mack MJ, Mauri L, Mehran R, Mukherjee D, Newby LK, O'Gara PT, Sabatine MS, Smith PK, Smith SC Jr. 2016 ACC/AHA guideline focused update on duration of dual antiplatelet therapy in patients with coronary artery disease: a report of the American College of Cardiology/American Heart Association Task Force on Clinical Practice Guidelines: an update of the 2011 ACCF/AHA/SCAI guideline for percutaneous coronary intervention, 2011 ACCF/AHA guideline for coronary artery bypass graft surgery, 2012 ACC/AHA/ACP/AATS/PCNA/SCAI/STS guideline for the diagnosis and management of patients with stable ischemic heart disease, 2013 ACCF/AHA guideline for the management of ST-elevation myocardial infarction,
}

2014 ACC/AHA guideline for the management of patients with non-ST-elevation acute coronary syndromes, and 2014 ACC/AHA guideline on perioperative cardiovascular evaluation and management of patients undergoing noncardiac surgery. Circulation. 2016;134:e123-55.

This article has been copublished in The Journal of the American College of Cardiology. It has been reprinted by The Journal of Thoracic and Cardiovascular Surgery.

DOI of original article: http://dx.doi.org/10.1161/CIR.0000000000000404.

Copies: This document is available on the World Wide Web sites of the American College of Cardiology (www.acc.org) and the American Heart Association (professional.heart.org). A copy of the document is available at http:// professional.heart.org/statements by using either "Search for Guidelines \& Statements" or the "Browse by Topic" area. To purchase additional reprints, call 843216-2533 or e-mail kelle.ramsay@wolterskluwer.com.

Expert peer review of AHA Scientific Statements is conducted by the AHA Office of Science Operations. For more on AHA statements and guidelines development, visit http://professional.heart.org/statements. Select the "Guidelines \& Statements" drop-down menu, then click "Publication Development."

Permissions: Multiple copies, modification, alteration, enhancement, and/or distribution of this document are not permitted without the express permission of the American Heart Association. Instructions for obtaining permission are located at http://www. heart.org/HEARTORG/General/Copyright-Permission-Guidelines_UCM_300404_ Article.jsp. A link to the "Copyright Permissions Request Form" appears on the right side of the page.

J Thorac Cardiovasc Surg 2016;152:1243-75

$0022-5223 / \$ 36.00$

(C) 2016 by the American College of Cardiology Foundation and the American Heart Association, Inc.

http://dx.doi.org/10.1016/j.jtcvs.2016.07.044 
Federico Gentile, MD, FACC, Samuel Gidding, MD, FAHA, Mark A. Hlatky, MD, FACC, FAHA, John S. Ikonomidis, MD, PhD, FAHA, José A. Joglar, MD, FACC, FAHA, Susan J. Pressler, PhD, RN, FAHA, and Duminda N. Wijeysundera, MD, PhD

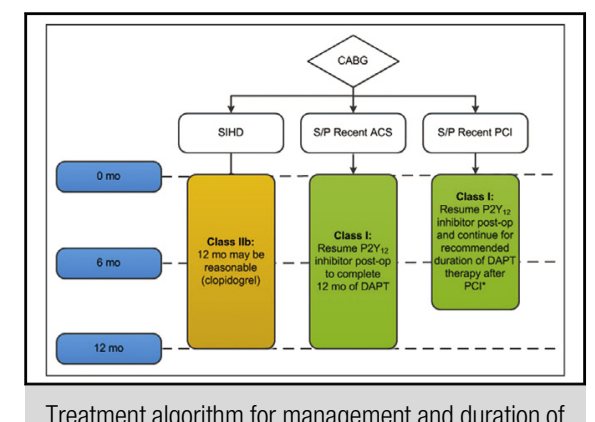

Treatment algorithm for management and duration of P2 $\mathrm{Y}_{12}$ inhibitor therapy in patients undergoing CABG.

See Editorial Commentary page 1276.

\section{TABLE OF CONTENTS}

Preamble . . . . . . . . . . . . . . . . . . . . . . . 1244

1. Introduction . . . . . . . . . . . . . . . . . . . 1246

1.1. Methodology and Evidence Review . . . . . . . . 1247

1.2. Organization of the Writing Group . . . . . . . . . 1247

1.3. Review and Approval . . . . . . . . . . . . . 1247

2. Critical Questions and Systematic Review Findings . . 1247

2.1. Critical Questions on Duration of DAPT . . . . . . 1247

2.2. Studies of Shorter-Duration DAPT After Stent Implantation. . . . . . . . . . . . . . . . . 1248

2.3. Studies of Longer-Duration DAPT After Stent Implantation. . . . . . . . . . . . . . . . . . . 1248

2.4. Other Studies Relevant to DAPT 1 Year After MI . 1248

2.5. Prolonged/Extended DAPT and Mortality Rate. . . 1249

3. Overriding Concepts and Recommendations for DAPT and

Duration of Therapy . . . . . . . . . . . . . . . . . 1249

3.1. General Overriding Concepts . . . . . . . . . . . 1249

3.2. Factors Associated With Increased Ischemic and Bleeding Risk . . . . . . . . . . . . . . 1249

3.3. Specific P2Y12 Inhibitors: Recommendations . . . . 1250

3.4. Platelet Function Testing, Genetic Testing, and Switching of P2Y12 Inhibitors......... 1251

3.5. Proton Pump Inhibitors and DAPT . . . . . . . . . 1252

3.6. Aspirin Dosing in Patients Treated With DAPT: Recommendation . . . . . . . . . . . . . 1252

3.7. Triple Therapy (Aspirin, P2Y12 Inhibitor, and Oral Anticoagulant) . . . . . . . . . . . . . . . . . 1253

4. Percutaneous Coronary Intervention . . . . . . . . . 1253

4.1. Duration of DAPT in Patients With SIHD Treated

With PCI: Recommendations . . . . . . . . . . . . 1253

4.2. Duration of DAPT in Patients With ACS Treated With PCI: Recommendations . . . . . . . . . . . 1253

4.3. Duration of DAPT in Patients With SIHD and ACS

Treated With PCI . . . . . . . . . . . . . . . . . . 1254

5. Recommendations for Duration of DAPT in Patients Undergoing CABG . . . . . . . . . . . . . . 1255
6. Recommendations for Duration of DAPT in Patients with SIHD . . . . . . . . . . . . . . 1256

7. Acute Coronary Syndrome (NSTE-ACS and STEMI) . 1258

7.1. Duration of DAPT in Patients With ACS Treated With Medical Therapy Alone (Without Revascularization or Fibrinolytic Th ... . . 1258

7.2. Duration of DAPT in Patients With STEMI Treated With Fibrinolytic Therapy: Recommendations . . . 1258

7.3. Duration of DAPT in Patients With ACS Treated With PCI: Recommendations . . . . . . . . . . . 1258

7.4. Duration of DAPT in Patients With ACS Treated With CABG: Recommendation . . . . . . . . . . 1259

7.5. Duration of DAPT in Patients With ACS. . . . . . 1259

8. Perioperative Management-Timing of Elective Noncardiac Surgery in Patients Treated With PCI and DAPT:

Recommendations. . . . . . . . . . . . . . . . . . . 1260

References . . . . . . . . . . . . . . . . . . . 1263

Appendix 1. Author Relationships With Industry and Other Entities (Relevant). . . . . . . . 1268

Appendix 2. Reviewer Relationships With Industry and Other Entities (Relevant). . . . . . . . . . . 1270

\section{PREAMBLE}

Incorporation of new study results, medications, or devices that merit modification of existing clinical practice guideline recommendations, or the addition of new recommendations, is critical to ensuring that guidelines reflect current knowledge, available treatment options, and optimum medical care. To keep pace with evolving evidence, the American College of Cardiology (ACC)/American Heart Association (AHA) Task Force on Clinical Practice Guidelines ("Task Force") has issued this focused update to revise existing guideline recommendations on the basis of recently published 
study data. This update has been subject to rigorous, multilevel review and approval, similar to the full guidelines. For specific focused update criteria and additional methodological details, please see the ACC/AHA guideline methodology manual. ${ }^{1}$

\section{Modernization}

Processes have evolved over time in response to published reports from the Institute of Medicine ${ }^{2,3}$ and ACC/AHA mandates, ${ }^{4-7}$ leading to adoption of a "knowledge byte" format. This process entails delineation of a recommendation addressing a specific clinical question, followed by concise text (ideally $<250$ words per recommendation) and hyperlinked to supportive evidence. This approach better accommodates time constraints on busy clinicians, facilitates easier access to recommendations via electronic search engines and other evolving technology,

TABLE 1. Applying class of recommendation and level of evidence to clinical strategies, interventions, treatments, or diagnostic testing in patient care* (updated August 2015)

\section{CLASS (STRENGTH) OF RECOMIMENDATION}

CLASS I (STRONG)
Suggested phrases for writing recommendations:
- Is recommended
- Is indicated/useful/effective/beneficial
- Should be performed/administered/other
- Comparative-Effectiveness Phrasest:
- Treatment/strategy A is recommended/indicated in
preference to treatment B
- Treatment A should be chosen over treatment B

Suggested phrases for writing recommendations:
- Is reasonable
- Can be useful/effective/beneficial
- Comparative-Effectiveness Phrasest:
- Treatment/strategy A is probably recommended/indicated in
preference to treatment B
- It is reasonable to choose treatment A
over treatment B

\begin{tabular}{l}
\hline CLASS IIh (WEARA \\
\hline Suggested phrases for writing recommendations: \\
- May/might be reasonable \\
- May/might be considered \\
- Usefulness/effectiveness is unknown/unclear/uncertain \\
or not well established
\end{tabular}

\begin{tabular}{l}
$\begin{array}{l}\text { CLASS Ill: No Benefit (MODERATE) Bencfit = Risk } \\
\text { (Genaraly LOE A ar a ise any) }\end{array}$ \\
\hline Suggested phrases for writing recommendations: \\
- Is not recommended \\
- Is not indicated/useful/effective/beneficial \\
- Should not be performed/administered/other
\end{tabular}

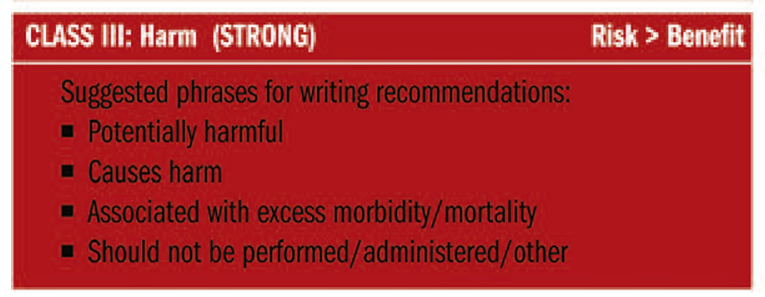

\section{LEVEL (QUALITY) OF EVIDENCE}

\begin{tabular}{l}
\hline LEVEL A \\
\hline - High-quality evidenceł from more than 1 RCT \\
- Meta-analyses of high-quality RCTs \\
- One or more RCTs corroborated by high-quality registry studies
\end{tabular}

LEVEL B-R (Randomized)

- Moderate-quality evidence from 1 or more RCTs

- Meta-analyses of moderate-quality RCTs

\begin{tabular}{l} 
LEVEL B-NR \\
\hline - Moderate-quality evidencef from 1 or more well-designed, \\
well-executed nonrandomized studies, observational \\
studies, or registry studies \\
- Meta-analyses of such studies
\end{tabular}

IEVEL C-ID
- Randomized or nonrandomized observational or registry
studies with limitations of design or execution
- Meta-analyses of such studies
- Physiological or mechanistic studies in human subjects
IEVEL. C-EO
Consensus of expert opinion based on clinical experience

COR and LOE are determined independently (any COR may be paired with any LOE).

A recommendation with $L O E C$ does not imply that the recommendation is weak. Many important clinical questions addressed in guidelines do not lend themselves to clinical trials. Although RCTs are unavailable, there may be a very clear clinical consensus that a particular test or therapy is useful or effective.

* The outcome or result of the intervention should be specified (an improved clinical outcome or increased diagnostic accuracy or incremental prognostic information).

† For comparative-effectiveness recommendations (COR I and Ila; LOE A and B only), studies that support the use of comparator verbs should involve direct comparisons of the treatments or strategies being evaluated.

$\ddagger$ The method of assessing quality is evolving, including the application of standardized, widely used, and preferably validated evidence grading tools; and for systematic reviews, the incorporation of an Evidence Review Committee.

COR indicates Class of Recommendation; EO, expert opinion; LD, limited data; LOE, Level of Evidence; NR, nonrandomized; R, randomized; and RCT, randomized controlled trial. 
and supports the evolution of guidelines as "living documents" that can be dynamically updated as needed.

\section{Class of Recommendation and Level of Evidence}

The Class of Recommendation (COR) and Level of Evidence (LOE) are derived independently of each other according to established criteria. The COR indicates the strength of recommendation, encompassing the estimated magnitude and certainty of benefit of a clinical action in proportion to risk. The LOE rates the quality of scientific evidence supporting the intervention on the basis of the type, quantity, and consistency of data from clinical trials and other sources (Table 1). Recommendations in this focused update reflect the new 2015 COR/LOE system, in which LOE B and C are subcategorized for the purpose of increased granularity. ${ }^{1,7,8}$

\section{Relationships With Industry and Other Entities}

The ACC and AHA exclusively sponsor the work of guideline writing committees (GWCs) without commercial support, and members volunteer time for this activity. Selected organizations and professional societies with related interests and expertise are invited to participate as partners or collaborators. The Task Force makes every effort to avoid actual, potential, or perceived conflicts of interest that might arise through relationships with industry or other entities (RWI). All GWC members and reviewers are required to fully disclose current industry relationships or personal interests, beginning 12 months before initiation of the writing effort. Management of RWI involves selecting a balanced GWC and requires that both the chair and a majority of GWC members have no relevant RWI (see Appendix 1 for the definition of relevance). GWC members are restricted with regard to writing or voting on sections to which RWI apply. Members of the GWC who recused themselves from voting are indicated and specific section recusals are noted in Appendixes 1 and 2. In addition, for transparency, GWC members' comprehensive disclosure information is available as an Online Supplement (http://circ.ahajournals.org/lookup/suppl/doi: 10.1161/CIR.0000000000000404/-/DC1). Comprehensive disclosure information for the Task Force is also available at http://www.acc.org/about-acc/leadership/guidelines-anddocuments-task-forces.aspx. The Task Force strives to avoid bias by selecting experts from a broad array of backgrounds representing different geographic regions, genders, ethnicities, intellectual perspectives, and scopes of clinical activities.

\section{Intended Use}

Guidelines provide recommendations applicable to patients with or at risk of developing cardiovascular disease. The focus is on medical practice in the United States, but guidelines developed in collaboration with other organizations may have a broader target. Although guidelines may be used to inform regulatory or payer decisions, the intent is to improve quality of care and align with patients' interests. The guidelines are reviewed annually by the Task Force and are official policy of the ACC and AHA. Each guideline is considered current unless and until it is updated, revised, or superseded by a published addendum.

\section{Related Issues}

For additional information pertaining to the methodology for grading evidence, assessment of benefit and harm, shared decision making between the patient and clinician, structure of evidence tables and summaries, standardized terminology for articulating recommendations, organizational involvement, peer review, and policies regarding periodic assessment and updating of guideline documents, we encourage readers to consult the ACC/AHA guideline methodology manual. ${ }^{1}$

Jonathan L. Halperin, MD, FACC, FAHA Chair, ACC/AHA Task Force on Clinical Practice

Guidelines

\section{INTRODUCTION}

The scope of this focused update is limited to addressing recommendations on duration of dual antiplatelet therapy (DAPT) (aspirin plus a P2 $\mathrm{Y}_{12}$ inhibitor) in patients with coronary artery disease (CAD). Recommendations considered are those in 6 guidelines: "2011 ACCF/AHA/SCAI Guideline for Percutaneous Coronary Intervention,"9 "2011 ACCF/AHA Guideline for Coronary Artery Bypass Graft Surgery," 10 "2012 ACCF/AHA/ACP/AATS/PCNA/SCAI/STS Guideline for the Diagnosis and Management of Patients With Stable Ischemic Heart Disease," 11,12 "2013 ACC/AHA Guideline for the Management of ST-Elevation Myocardial Infarction,"13 "2014 ACC/AHA Guideline for Non-ST-Elevation Acute Coronary Syndromes," 14 and "2014 ACC/AHA Guideline on Perioperative Cardiovascular Evaluation and Management of Patients Undergoing Noncardiac Surgery."15

The impetus for this focused update review is 11 studies $^{16-27}$ of patients treated with coronary stent implantation (predominantly with drug-eluting stents [DES]) assessing shorter-duration or longer-duration DAPT, as well as a large, randomized controlled trial (RCT) of patients 1 to 3 years after myocardial infarction (MI) assessing the efficacy of DAPT compared with aspirin monotherapy. ${ }^{28}$ These studies were published after the formulation of recommendations for duration of DAPT in prior guidelines. The specific mandate of the present writing group is to evaluate, update, harmonize, and, when possible, simplify recommendations on duration of DAPT.

Although there are several potential combinations of antiplatelet therapy, the term and acronym $D A P T$ has been used to specifically refer to combination antiplatelet therapy with aspirin and a $\mathrm{P} 2 \mathrm{Y}_{12}$ receptor inhibitor (clopidogrel, prasugrel, or ticagrelor) and will be used similarly in this focused update. Recommendations in this focused update on duration of DAPT, aspirin dosing in patients treated with DAPT, and timing of elective noncardiac surgery in 
patients treated with percutaneous coronary intervention (PCI) and DAPT supersede prior corresponding recommendations in the 6 relevant guidelines. These recommendations for duration of DAPT apply to newer-generation stents and, in general, only to those not treated with oral anticoagulant therapy. For the purposes of this focused update, patients with a history of acute coronary syndrome (ACS) $>1$ year prior who have since remained free of recurrent ACS are considered to have transitioned to stable ischemic heart disease (SIHD) and are addressed in the section on SIHD. Issues and recommendations with regard to $\mathrm{P}^{2} \mathrm{Y}_{12}$ inhibitor "pretreatment," "preloading," and loading are beyond the scope of this document but are addressed in other guidelines. ${ }^{9,14,29}$

This focused update is designed to function both as a standalone document and to serve as an update to the relevant sections on duration of DAPT in the 6 clinical practice guidelines, replacing relevant text, figures, and recommendations. Thus, by necessity, there is some redundancy in different sections of this document. When possible, the "knowledge byte" format was used for recommendations. In some cases, the complexity of this document required a modification of the knowledge byte format, with several interrelated recommendations grouped together, followed by concise associated text $(<250$ words of text per recommendation).

\subsection{Methodology and Evidence Review}

Clinical trials published since the 2011 PCI guideline ${ }^{9}$ and the 2011 coronary artery bypass graft (CABG) guideline, ${ }^{10}$ published in a peer-reviewed format through December 2015, were reviewed by the Task Force to identify trials and other key data that might affect guideline recommendations. The information considered important enough to prompt updated recommendations is included in evidence tables in the Online Data Supplement.

In accord with recommendations by the Institute of Medicine $^{2,3}$ and the ACC/AHA Task Force Methodology Summit, ${ }^{1,6} 3$ critical (PICOTS-formatted; population, intervention, comparison, outcome, timing, setting) questions were developed to address the critical questions related to duration of DAPT. These 3 critical questions were the basis of a formal systematic review and evaluation of the relevant study data by an Evidence Review Committee (ERC). ${ }^{30}$ Concurrent with this process, writing group members evaluated study data relevant to the numerous current recommendations in the 6 guidelines, including topics not covered in the 3 critical questions (eg, DAPT after CABG). The findings of the ERC and the writing group members were formally presented and discussed, and then modifications to existing recommendations were considered. Recommendations that are based on a body of evidence that includes a systematic review conducted by the ERC are denoted by the superscript SR (eg,
LOE B-R ${ }^{S R}$ ). See the ERC systematic review report, "Duration of Dual Antiplatelet Therapy: A Systematic Review for the 2016 ACC/AHA Guideline Focused Update on Duration of Dual Antiplatelet Therapy in Patients With Coronary Artery Disease," for the complete evidence review report. ${ }^{30}$

\subsection{Organization of the Writing Group}

Recommendations on duration of DAPT are currently included in 6 clinical practice guidelines, which are interrelated and overlapping because they address the management of patients with CAD. Therefore, the writing group consisted of the chairs/vice chairs and/or members of all 6 guidelines, representing the fields of cardiovascular medicine, interventional cardiology, cardiac surgery, internal medicine, and cardiovascular anesthesia, as well as expertise in trial design and statistical analysis.

\subsection{Review and Approval}

This focused update was reviewed by the writing committee members from the 6 guidelines; by 5 official reviewers from the ACC and AHA; 2 reviewers each from the American Association for Thoracic Surgery, American College of Emergency Physicians, American Society of Anesthesiologists, Preventive Cardiovascular Nurses Association, Society for Cardiovascular Angiography and Interventions, Society of Cardiovascular Anesthesiologists, and the Society of Thoracic Surgeons; and by 23 additional content reviewers. Reviewers' RWI information is published in this document (Appendix 2).

This document was approved for publication by the governing bodies of the ACC and the AHA and was endorsed by the American Association for Thoracic Surgery, American Society of Anesthesiologists, Preventive Cardiovascular Nurses Association, Society for Cardiovascular Angiography and Interventions, Society of Cardiovascular Anesthesiologists, Society of Thoracic Surgeons, and Society for Vascular Surgery.

\section{CRITICAL QUESTIONS AND SYSTEMATIC REVIEW FINDINGS}

\subsection{Critical Questions on Duration of DAPT}

The 3 critical (PICOTS-formatted) questions on DAPT duration are listed in Table 2. Most contemporary studies of DAPT have compared either shorter (3 to 6 months) ${ }^{17-21}$ or longer (18 to 48 months) ${ }^{16,22-26}$ duration of therapy with 12 months of DAPT, which is the recommended or minimal duration of therapy for most patients in ACC/AHA ${ }^{9,13,14}$ and European Society of Cardiology ${ }^{31-33}$ guidelines published between 2011 and 2014. Recommendations based on the findings from the critical question-focused systemic reviews are provided in Sections 4 to 8 of the present document. 
TABLE 2. Critical (PICOTS-formatted) questions on DAPT duration

Q1: In patients treated with newer (non-first) generation DES for (1) SIHD or (2) ACS, compared with 12 months of DAPT, is 3-6 months of DAPT as effective in preventing stent thrombosis, preventing MACE and/or reducing bleeding complications?

Q2: In patients treated with newer (non-first) generation DES, compared with 12 months of DAPT, does $>12$ (18-48) months of DAPT result in differences in mortality rate, decreased MACE, decreased stent thrombosis, and/or increased bleeding?

Q3: In post-MI (NSTEMI or STEMI) patients who are clinically stable and $>12$ months past their event, does continued DAPT, compared with aspirin monotherapy, result in differences in mortality rate, decreased nonfatal MI, decreased MACE, and/or increased bleeding?

SIHD, Stable ischemic heart disease; $A C S$, acute coronary syndrome; DAPT, dual antiplatelet therapy; $M A C E$, major adverse cardiac events; $D E S$, drug-eluting stents; $M I$, myocardial infarction; NSTEMI, non-ST-elevation myocardial infarction; STEMI, ST-elevation myocardial infarction.

\subsection{Studies of Shorter-Duration DAPT After Stent Implantation}

Five RCTs of patients treated with elective DES implantation have compared shorter-duration (3 to 6 months) DAPT with 12 months of DAPT ${ }^{17-21}$ (Data Supplement 1). The trials primarily enrolled low-risk (non-ACS) patients, with only a small proportion having had a recent MI. The main endpoints of these noninferiority trials were composite ischemic events (or net composite events) and stent thrombosis. These studies, as well as several meta-analyses ${ }^{34-37}$ and an analysis by the ERC, ${ }^{30}$ did not find any increased risk of stent thrombosis with shorter-duration DAPT. A shorter duration of DAPT results in fewer bleeding complications. ${ }^{30,34-36}$ Shorter-duration DAPT may be most reasonable in patients currently being treated with "newergeneration" (eg, everolimus- or zotarolimus-eluting) DES, which are associated with lower stent thrombosis and MI rates than those of "first-generation" (eg, sirolimus- and paclitaxel-eluting) DES, which are rarely, if ever, used in current clinical practice. ${ }^{16,36,38}$

\subsection{Studies of Longer-Duration DAPT After Stent Implantation}

Six RCTs, consisting predominantly of patients treated with elective DES implantation, compared prolonged DAPT (total therapy duration: 18 to 48 months) with 6 to 12 months of DAPT to determine whether extended therapy reduces late and very late stent thrombosis and prevents ischemic events associated with disease progression and plaque rupture at other nonstented sites ${ }^{16,22-27}$ (Data Supplement 2). In the Dual Antiplatelet Therapy studythe largest of these trials-patients who had undergone DES implantation, had been treated with DAPT for 12 months, and were without ischemic or bleeding events during this period were randomized to an additional 18 months of DAPT or to aspirin monotherapy. ${ }^{16}$ Extended
DAPT resulted in a $0.7 \%$ absolute reduction in very late stent thrombosis, a $2.0 \%$ absolute reduction in MI, a $1.6 \%$ absolute reduction in major adverse cardiac events (MACE), and a $0.9 \%$ absolute increase in moderate or severe bleeding. In the subgroup of patients treated with everolimus-eluting stents-currently the most commonly used stent-extended DAPT resulted in a $0.4 \%$ absolute reduction in stent thrombosis, a $1.1 \%$ absolute reduction in MI, and a $1.2 \%$ absolute increase in moderate/severe bleeding. $^{39}$

Taken as a whole, studies of longer-duration ("prolonged" or "extended") DAPT ${ }^{16,22-27}$ for an additional 18 to 36 months after DES found an absolute decrease in late stent thrombosis and ischemic complications of $\approx 1 \%$ to $2 \%$ and an absolute increase in bleeding complications of $\approx 1 \%$ (Data Supplements 2 and 3). A weighted riskbenefit analysis by the ERC of studies of patients treated with DES found 6 fewer MIs and 3 fewer stent thromboses but 5 additional major bleeds per 1000 patients treated with prolonged DAPT per year. ${ }^{30}$

\subsection{Other Studies Relevant to DAPT $>1$ Year After MI}

The CHARISMA (Clopidogrel for High Atherothrombotic Risk and Ischemic Stabilization, Management, and Avoidance) trial randomized patients with established atherosclerosis or at high risk of clinical atherosclerotic disease to either DAPT (with clopidogrel) or aspirin monotherapy; with DAPT, no significant reduction was found in ischemic effects at a median follow-up of 28 months, but there was a $0.4 \%$ absolute increase in severe bleeding. ${ }^{40}$ A post hoc analysis of patients enrolled in the study with prior MI found a $1.7 \%$ absolute decrease in the composite endpoint of cardiovascular death, MI, or stroke events with DAPT, with no benefit in those with CAD without prior MI. ${ }^{40,41}$

Patients in the PEGASUS-TIMI 54 (Prevention of Cardiovascular Events in Patients with Prior Heart Attack Using Ticagrelor Compared to Placebo on a Background of Aspirin-Thrombolysis In Myocardial Infarction 54) trial were randomized 1 to 3 years after MI with additional high-risk features to either DAPT (with ticagrelor $60 \mathrm{mg}$ or $90 \mathrm{mg}$ twice daily) or continued aspirin monotherapy. ${ }^{28}$ After a mean of 33 months of therapy, DAPT, when compared with aspirin monotherapy, resulted in a $1.2 \%$ to $1.3 \%$ absolute reduction in the primary composite endpoint of cardiovascular death, MI, or stroke and a $1.2 \%$ to $1.5 \%$ absolute increase in major bleeding, with no excess in fatal bleeding or intracranial hemorrhage. In subgroup analysis, the greatest reduction in ischemic events with prolonged DAPT was in patients in whom $\mathrm{P}_{2} \mathrm{Y}_{12}$ inhibitor therapy either had not been discontinued or had been discontinued for $\leq 30$ days (absolute reduction in MACE: 
$1.9 \%$ to $2.5 \%$ ). No benefit was seen in patients in whom $\mathrm{P}_{2} \mathrm{Y}_{12}$ inhibitor therapy had been discontinued $>1$ year before enrollment in the study. ${ }^{42}$

In the Dual Antiplatelet Therapy study, the benefit/risk ratio for prolonged DAPT was more favorable for those presenting with MI than those with SIHD. ${ }^{43}$ In an analysis of patients with a history of prior MI enrolled in 6 RCTs of extended/prolonged DAPT, extended DAPT significantly decreased the absolute risk of MACE by $1.1 \%$ and significantly increased the absolute risk of major bleeding by $0.8 \%{ }^{44}$

Taken as a whole, trials of prolonged or extended DAPT suggest that the benefit/risk ratio of prolonged DAPT may be more favorable for those with prior MI, with an absolute decrease in ischemic events of $\approx 1 \%$ to $3 \%$ at the cost of an absolute increase in bleeding events of $\approx 1 \%$ over the course of several years of prolonged or extended therapy (median durations of therapy: 18 to 33 months) (Data Supplements 3 and 4). This appears biologically plausible because patients with prior MI (usually mediated by plaque rupture) may be at greater risk for future plaque rupture than those without prior MI. ${ }^{37,40,41}$

\subsection{Prolonged/Extended DAPT and Mortality Rate}

An unexpected finding in the Dual Antiplatelet Therapy study ${ }^{16}$ was a borderline-significant increase in overall mortality rate $(0.5 \%$ absolute increase $)$ with 30 months of DAPT versus 12 months of DAPT in DES-treated patients, which was due to significantly increased deaths from noncardiovascular causes (most commonly cancer), with no increase in cardiovascular deaths, and no significant increase in fatal bleeding. ${ }^{45}$ Five subsequent meta-analyses $^{35-37,46,47}$ restricted to RCTs of studies enrolling patients treated with predominantly newer generation DES, published prior to the presentation of the OPTIDUAL (Optimal Dual Antiplatelet Therapy) trial, found numerically ${ }^{36,47}$ or statistically ${ }^{35,37,46}$ significant increased risk of all-cause (though not cardiovascular) death associated with prolonged duration of DAPT (Data Supplements 3 and 4).

In contrast, a meta-analysis that combined studies of DAPT duration after stent implantation with studies of DAPT duration for other indications ${ }^{48}$ and an analysis of 6 trials restricted to post-MI patients treated with DAPT ${ }^{44}$ found no increase in cardiovascular or noncardiovascular mortality rate associated with prolonged DAPT (Data Supplement 3). A US Food and Drug Administration drug safety communication, based on an evaluation of longterm clinical trials of patients with cardiovascular disease or stroke treated with clopidogrel, concluded that longterm clopidogrel treatment did not increase the risk of allcause death or cancer-related death. ${ }^{49}$ The primary analysis by the ERC of 11 RCTs (including OPTIDUAL) compared use of DAPT for 18 to 48 months with use of DAPT for 6 to
12 months in patients who had received predominantly newer-generation DES and found no statistically significant difference in all-cause mortality rate. ${ }^{30}$

A majority of writing group members believe the data as a whole do not seem to suggest prolonged DAPT results in increased mortality.

\section{OVERRIDING CONCEPTS AND RECOMMENDATIONS FOR DAPT AND DURATION OF THERAPY}

\subsection{General Overriding Concepts}

Overriding concepts and relevant recommendations for DAPT and duration of therapy are summarized in Table 3. Intensification of antiplatelet therapy, with the addition of a $\mathrm{P}_{2} \mathrm{Y}_{12}$ inhibitor to aspirin monotherapy, necessitates a fundamental tradeoff between decreasing ischemic risk and increasing bleeding risk. ${ }^{40,41,50-52}$ Similarly, longer compared with shorter duration of DAPT generally results in decreased ischemic risk at the expense of increased bleeding risk. ${ }^{16,24,28,30,46}$ Use of more potent $\mathrm{P}_{2} \mathrm{Y}_{12}$ inhibitors (ticagrelor or prasugrel) in place of clopidogrel also results in decreased ischemic risk and increased bleeding risk. ${ }^{53-55}$

In general, recommendations for duration of DAPT in the present focused update consist of a Class I recommendation ("should be given") for a minimum period of time (in most cases 6 to 12 months) and a Class IIb recommendation ("may be considered") for continuation of DAPT beyond that period of time. Shorter-duration DAPT can be considered for patients at lower ischemic risk with high bleeding risk, whereas longer-duration DAPT may be reasonable for patients at higher ischemic risk with lower bleeding risk. These recommendations do not generally apply to patients treated with oral anticoagulant therapy, who were excluded from almost all studies of DAPT duration and who are at significantly increased bleeding risk (as discussed in Section 3.4). Decisions about duration of DAPT are best made on an individual basis and should integrate clinical judgment, assessment of the benefit/risk ratio, and patient preference. Aspirin therapy is almost always continued indefinitely in patients with CAD, and recommendations on duration of DAPT should be taken to mean the recommended duration of $\mathrm{P}_{2} \mathrm{Y}_{12}$ inhibitor therapy (in addition to aspirin therapy). Figure 1 summarizes recommendations for duration of DAPT according to clinical status.

\subsection{Factors Associated With Increased Ischemic and Bleeding Risk}

Factors that have been associated with increased ischemic risk (including increased risk of stent thrombosis) and increased bleeding risk are listed in Table 4. Individual patients may have factors for both increased ischemic and bleeding risk, and some factors are associated with both 
TABLE 3. Overriding concepts and updated recommendations for DAPT and duration

Intensification of antiplatelet therapy, with the addition of a $\mathrm{P}_{2} \mathrm{Y}_{12}$ inhibitor to aspirin monotherapy, as well as prolongation of DAPT, necessitates a fundamental tradeoff between decreasing ischemic risk and increasing bleeding risk. Decisions about treatment with and duration of DAPT require a thoughtful assessment of the benefit/risk ratio, integration of study data, and consideration of patient preference.

In general, shorter-duration DAPT can be considered for patients at lower ischemic risk with high bleeding risk, whereas longer-duration DAPT may be reasonable for patients at higher ischemic risk with lower bleeding risk.

Prior recommendations for duration of DAPT for patients treated with DES were based on data from "first-generation" DES, which are rarely if ever used in current clinical practice. Compared with first-generation stents, newer-generation stents have an improved safety profile and lower risk of stent thrombosis. Recommendations in this focused update apply to newer-generation stents.

Updated recommendations for duration of DAPT are now similar for patients with NSTE-ACS and STEMI, as both are part of the spectrum of acute coronary syndrome.

A Class I recommendation ("should be given") in most clinical settings is made for at least 6-12 months of DAPT (depending on the setting), and a Class IIb recommendation ("may be reasonable") is made for prolonged DAPT beyond this initial 6- to 12-month period.

In studies of prolonged DAPT after DES implantation or after MI, duration of therapy was limited to several years (akin to many other studied therapies). Thus, in patients for whom the benefit/risk ratio seemingly favors prolonged therapy, the true optimal duration of therapy is unknown.

Recommendations in the document apply specifically to duration of $\mathrm{P} 2 \mathrm{Y}_{12}$ inhibitor therapy in patients with CAD treated with DAPT. Aspirin therapy should almost always be continued indefinitely in patients with CAD.

Lower daily doses of aspirin, including in patients treated with DAPT, are associated with lower bleeding complications and comparable ischemic protection $^{56-60}$ than are higher doses of aspirin. The recommended daily dose of aspirin in patients treated with DAPT is $81 \mathrm{mg}$ (range, $75 \mathrm{mg}$ to $100 \mathrm{mg})$.

$D A P T$, Dual antiplatelet therapy; $D E S$, drug-eluting stent; $N S T E-A C S$, non-ST-elevation acute coronary syndrome; STEMI, ST-elevation myocardial infarction; $M I$, myocardial infarction; $C A D$, coronary artery disease.

increased ischemic and bleeding risk, making it difficult in many patients to assess the benefit/risk ratio of prolonged DAPT.

A new risk score (the "DAPT score"), derived from the Dual Antiplatelet Therapy study, may be useful for decisions about whether to continue (prolong or extend) DAPT in patients treated with coronary stent implantation. Analysis of study data suggests that in patients treated for 1 year with DAPT without significant bleeding or ischemic events, the benefit/risk ratio with prolonged DAPT may be favorable for those with a high DAPT score $(\geq 2)$ because prolonged DAPT reduces net (ischemic plus bleeding) events when compared with nonprolonged DAPT. ${ }^{61}$ Conversely, in those with a low DAPT score $(<2)$, the benefit/risk ratio with prolonged DAPT is not favorable (increased bleeding without a reduction in ischemic events). Factors that contribute to a high DAPT score include diabetes mellitus, current cigarette use, prior PCI or prior MI, congestive heart failure or left ventricular ejection fraction $<30 \%$, MI at presentation, vein graft PCI, and stent diameter $<3 \mathrm{~mm}$; older age contributes to a low (less favorable) DAPT score. Factors and their weighting used to calculate a DAPT score are provided in Table 5.

\subsection{Specific $\mathrm{P}_{2} \mathrm{Y}_{12}$ Inhibitors: Recommendations}

See Online Data Supplement 5 for evidence supporting these recommendations.

\begin{tabular}{|c|c|l|}
\hline \multicolumn{3}{|c|}{ Recommendations for Specific P2Y $_{12}$ Inhibitors } \\
\hline COR & LOE & Recommendations \\
\hline Ila & B-R & $\begin{array}{l}\text { In patients with ACS (NSTE-ACS or STEMI) treated } \\
\text { with DAPT after coronary stent implantation and in } \\
\text { patients with NSTE-ACS treated with medical therapy } \\
\text { alone (without revascularization), it is reasonable } \\
\text { to use ticagrelor in preference to clopidogrel for } \\
\text { maintenance P2Y }\end{array}$ \\
\hline Ila & inhibitor therapy. ${ }^{53,71,72}$ \\
\hline III: Harm & B-R & $\begin{array}{l}\text { In patients with ACS (NSTE-ACS or STEMI) treated with } \\
\text { DAPT after coronary stent implantation who are not at } \\
\text { high risk for bleeding complications and who do not } \\
\text { have a history of stroke or TIA, it is reasonable to } \\
\text { choose prasugrel over clopidogrel for maintenance } \\
\text { P2Y }\end{array}$ \\
\hline inhibitor therapy. ${ }^{54,55}$
\end{tabular}

In the PLATO (Platelet Inhibition and Patient Outcomes) trial, ${ }^{53}$ patients with ACS were treated with either medical therapy alone or medical therapy plus PCI. Treatment with ticagrelor $90 \mathrm{mg}$ twice daily, compared with clopidogrel $75 \mathrm{mg}$ once daily, resulted in fewer ischemic complications and stent thromboses but more frequent non-CABG-related bleeding (Data Supplement 5). In the TRITON-TIMI 38 (Therapeutic Outcomes by Optimizing Platelet Inhibition With Prasugrel-Thrombolysis In Myocardial Infarction 38) ${ }^{54}$ study, patients with ACS undergoing planned PCI were treated with prasugrel 10 mg daily, compared with clopidogrel $75 \mathrm{mg}$ daily. Prasugrel treatment resulted in fewer ischemic complications and stent thromboses but more frequent bleeding, including life-threatening and fatal bleeding. Because of increased rates of major bleeding with prasugrel (compared with clopidogrel), there was no net benefit of prasugrel therapy in those $\geq 75$ years of age and those $<60 \mathrm{~kg}$, and there was net harm (including increased risk of intracranial hemorrhage) in those with prior stroke or transient ischemic attack (TIA). The Class IIa preferential recommendations for ticagrelor $90 \mathrm{mg}$ twice daily and 


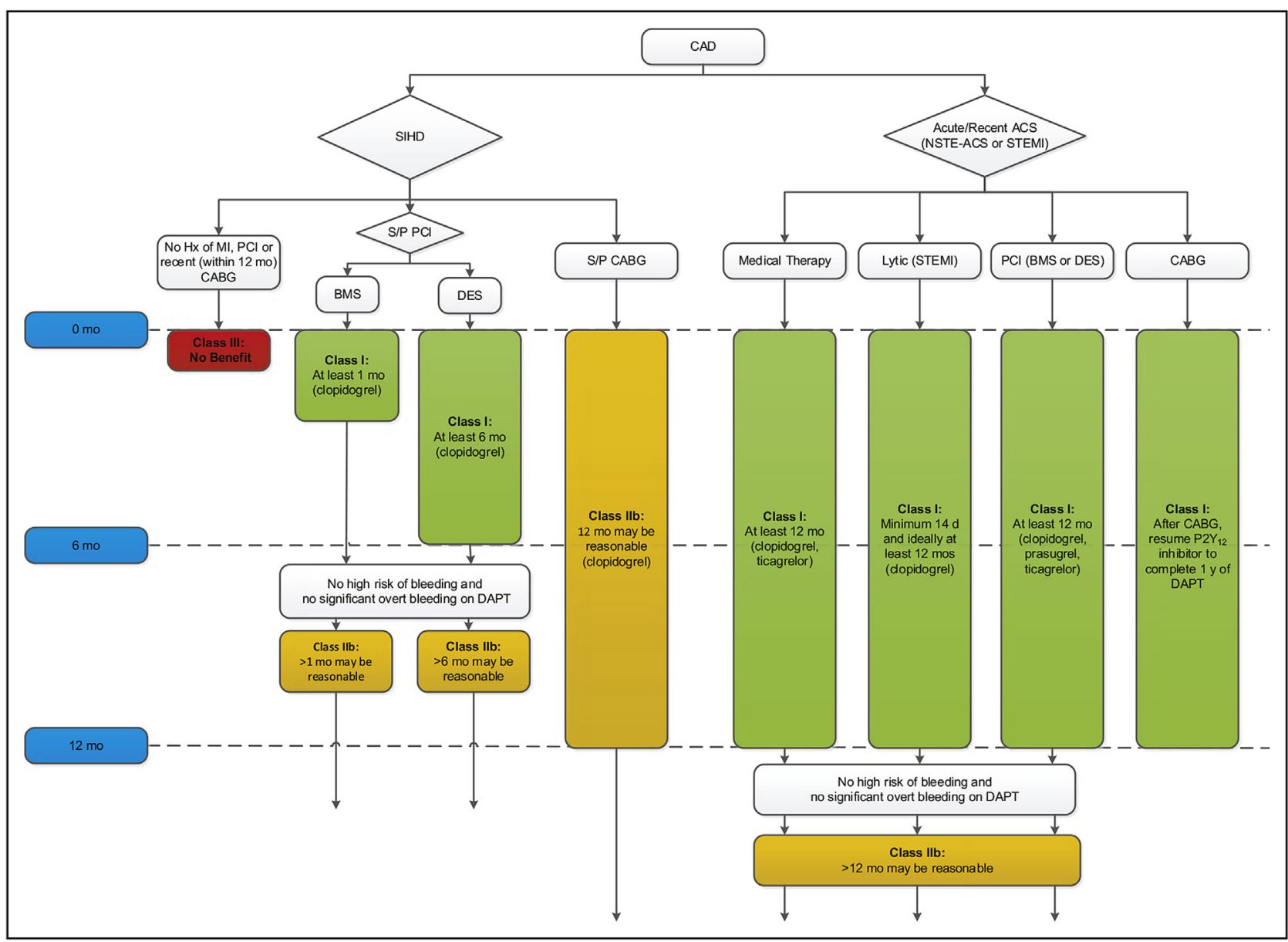

FIGURE 1. Master treatment algorithm for duration of $\mathrm{P} 2 \mathrm{Y}_{12}$ inhibitor therapy in patients with CAD treated with DAPT. Colors correspond to Class of Recommendation in Table 1. Clopidogrel is the only currently used P2 $\mathrm{Y}_{12}$ inhibitor studied in patients with SIHD undergoing PCI. Aspirin therapy is almost always continued indefinitely in patients with CAD. Patients with a history of ACS $>1$ year prior who have since remained free of recurrent ACS are considered to have transitioned to SIHD. In patients treated with DAPT after DES implantation who develop a high risk of bleeding (eg, treatment with oral anticoagulant therapy), are at high risk of severe bleeding complication (eg, major intracranial surgery), or develop significant overt bleeding, discontinuation of P2Y 12 inhibitor therapy after 3 months for SIHD or after 6 months for ACS may be reasonable. Arrows at the bottom of the figure denote that the optimal duration of prolonged DAPT is not established. CAD, Coronary artery disease; SIHD, stable ischemic heart disease; ACS, acute coronary syndrome; NSTE$A C S$, non-ST-elevation acute coronary syndrome; STEMI, ST-elevation myocardial infarction; $H x$, history; $P C I$, percutaneous coronary intervention; $C A B G$, coronary artery bypass graft surgery; Lytic, fibrinolytic therapy; $S / P$, status post; $B M S$, bare metal stent; $D E S$, drug-eluting stent; $D A P T$, dual antiplatelet therapy.

for prasugrel $10 \mathrm{mg}$ once daily (compared with clopidogrel) in the 2014 Non-ST-Elevation Acute Coronary Syndromes (NSTE-ACS) guideline are continued in this focused update and are now included in relevant PCI and ST-Elevation Myocardial Infarction (STEMI) recommendations, as well.

In the PEGASUS-TIMI 54 study of post-MI patients, both $60-\mathrm{mg}$ and $90-\mathrm{mg}$ twice-daily doses of ticagrelor were evaluated. ${ }^{28}$ The benefit/risk ratio appears to be numerically more favorable for the $60-\mathrm{mg}$ dose, although no formal statistical comparison was made between results of the 2 dosing regimens. The $60-\mathrm{mg}$ twice-daily dose has now been approved by the US Food and Drug
Administration for reduction in ischemic events in patients with ACS or a history of MI. ${ }^{73}$

\subsection{Platelet Function Testing, Genetic Testing, and Switching of $\mathrm{P2Y}_{12}$ Inhibitors}

The role of platelet function testing and genetic testing in patients treated with DAPT is addressed in the 2011 ACCF/ AHA/SCAI PCI guideline and the 2014 ACC/AHA NSTEACS guideline. ${ }^{9,14}$ To date, no RCT has demonstrated that routine platelet function testing or genetic testing to guide $\mathrm{P}_{2} \mathrm{Y}_{12}$ inhibitor therapy improves outcome; thus, the routine use of platelet function and genetic testing is not recommended (Class III: No Benefit). 
TABLE 4. Clinical and procedural factors associated with increased ischemic risk (including stent thrombosis) or increased bleeding risk $^{62-70}$

\begin{tabular}{|c|c|}
\hline $\begin{array}{c}\text { Increased ischemic } \\
\text { risk/risk of stent } \\
\text { thrombosis (may favor } \\
\text { longer-duration DAPT) } \\
\end{array}$ & $\begin{array}{c}\text { Increased bleeding } \\
\text { risk (may favor } \\
\text { shorter-duration DAPT) }\end{array}$ \\
\hline $\begin{array}{l}\text { Increased ischemic risk } \\
\text { Advanced age } \\
\text { ACS presentation } \\
\text { Multiple prior MIs } \\
\text { Extensive CAD } \\
\text { Diabetes mellitus } \\
\text { CKD } \\
\text { Increased risk of stent thrombosis } \\
\text { ACS presentation } \\
\text { Diabetes mellitus } \\
\text { Left ventricular ejection } \\
\text { fraction <40\% } \\
\text { First-generation drug-eluting stent } \\
\text { Stent undersizing } \\
\text { Stent underdeployment } \\
\text { Small stent diameter } \\
\text { Greater stent length } \\
\text { Bifurcation stents } \\
\text { In-stent restenosis }\end{array}$ & $\begin{array}{l}\text { History of prior bleeding } \\
\text { Oral anticoagulant therapy } \\
\text { Female sex } \\
\text { Advanced age } \\
\text { Low body weight } \\
\text { CKD } \\
\text { Diabetes mellitus } \\
\text { Anemia } \\
\text { Chronic steroid or NSAID therapy }\end{array}$ \\
\hline
\end{tabular}

No randomized data are available on the long-term safety or efficacy of "switching" patients treated for weeks or months with a $\mathrm{P} 2 \mathrm{Y}_{12}$ inhibitor to a different $\mathrm{P} 2 \mathrm{Y}_{12}$ inhibitor.

\subsection{Proton Pump Inhibitors and DAPT}

The use of proton pump inhibitors (PPIs) in patients treated with DAPT is discussed in a 2010 ACCF/ACG/

TABLE 5. Factors used to calculate a "DAPT score"

\begin{tabular}{lr}
\hline \multicolumn{1}{c}{ Variable } & Points \\
\hline Age $\geq 75$ y & -2 \\
Age 65 to $<75$ y & -1 \\
Age $<65$ y & 0 \\
Current cigarette smoker & 1 \\
Diabetes mellitus & 1 \\
MI at presentation & 1 \\
Prior PCI or prior MI & 1 \\
Stent diameter $<3$ mm & 1 \\
Paclitaxel-eluting stent & 1 \\
CHF or LVEF $<30 \%$ & 2 \\
Saphenous vein graft PCI & 2 \\
\hline A score of $\geq 2$ is associated with a favorable benefit/risk ratio for prolonged DAPT \\
while a score of $<2$ is associated with an unfavorable benefit/risk ratio. $M I$, Myocar- \\
dial infarction; $P C I$, percutaneous coronary intervention; $C H F$, congestive heart fail- \\
ure; $L V E F$, left ventricular ejection fraction. Adapted with permission from Yeh \\
et al. ${ }^{61}$
\end{tabular}

AHA expert consensus document. ${ }^{74}$ Recommendations on the use of PPIs are given in the 2011 ACCF/AHA/SCAI PCI guideline. ${ }^{9}$ PPIs should be used in patients with a history of prior gastrointestinal bleeding treated with DAPT (Class I). In patients with increased risk of gastrointestinal bleeding, including those with advanced age and those with concomitant use of warfarin, steroids, or nonsteroidal anti-inflammatory drugs, use of PPIs is reasonable (Class IIa). Routine use of PPIs is not recommended for patients at low risk of gastrointestinal bleeding (Class III: No Benefit).

\subsection{Aspirin Dosing in Patients Treated With DAPT: Recommendation}

See Online Data Supplement 6 for evidence supporting this recommendation.

Recommendation for Aspirin Dosing in Patients Treated With DAPT

\begin{tabular}{|c|c|l|}
\hline COR & LOE & Recommendation \\
\hline I & B-NR & $\begin{array}{l}\text { In patients treated with DAPT, a daily aspirin } \\
\text { dose of } 81 \mathrm{mg}(\text { range, } 75 \mathrm{mg} \text { to } 100 \mathrm{mg} \text { ) is } \\
\text { recommended. }{ }^{56-60,75-78}\end{array}$ \\
\hline
\end{tabular}

Because aspirin dosing recommendations across ACC/ AHA clinical practice guidelines are not consistent with regard to dose or class of recommendation, and because aspirin is a component of DAPT, a comprehensive review of these issues was undertaken. Large overviews, including studies of nearly 200,000 persons, have consistently shown that lower aspirin doses ( $\leq 100 \mathrm{mg}$ daily) are associated with less major and total bleeding than are higher doses, either when used as monotherapy or when combined with the P2 $\mathrm{Y}_{12}$ inhibitor clopidogrel. ${ }^{56,58,75,76,78}$ Daily aspirin doses as low as $30 \mathrm{mg}$ to $50 \mathrm{mg}$ inactivate the platelet cyclo-oxygenase-1 enzyme and inhibit thromboxane production. ${ }^{79-81}$ Studies comparing lower $(75 \mathrm{mg}$ to $150 \mathrm{mg}$ ) with higher aspirin doses have consistently found comparable ischemic event rates with either dose when used as monotherapy or when combined with the $\mathrm{P} 2 \mathrm{Y}_{12}$ inhibitor clopidogrel. ${ }^{56-60,78}$ The efficacy of ticagrelor seems to be decreased in patients treated with higher aspirin doses ( $\geq 300 \mathrm{mg}$ daily) versus lower aspirin doses $(\leq 100 \mathrm{mg}$ daily $){ }^{82}$ On the basis of available data, the optimal range of aspirin dose in patients treated with DAPT that provides maximal protection from ischemic events and minimizes bleeding risk appears to be $75 \mathrm{mg}$ to $100 \mathrm{mg}$ (Data Supplement 6). For practical purposes, because the relevant aspirin dose available in the United States is $81 \mathrm{mg}$, this maintenance dose is recommended in patients with CAD treated with DAPT. The ongoing ADAPTABLE (Aspirin Dosing: A Patient-Centric Trial 
TABLE 6. Summary and synthesis of guideline, expert consensus documents, and comprehensive review article recommendations on the management of patients treated with triple therapy ${ }^{14,88,91-93}$

Assess ischemic and bleeding risks using validated risk predictors (eg,

$\mathrm{CHA}_{2} \mathrm{DS}_{2}$-VASc, HAS-BLED)

Keep triple therapy duration as short as possible; dual therapy only (oral anticoagulant and clopidogrel) may be considered in select patients

Consider a target INR of 2.0-2.5 when warfarin is used

Clopidogrel is the $\mathrm{P}_{2} \mathrm{Y}_{12}$ inhibitor of choice

Use low-dose ( $\leq 100 \mathrm{mg}$ daily) aspirin

PPIs should be used in patients with a history of gastrointestinal bleeding and are reasonable to use in patients with increased risk of

gastrointestinal bleeding

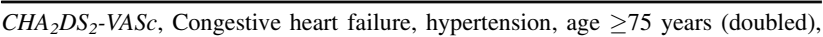
diabetes mellitus, prior stroke or transient ischemic attack or thromboembolism (doubled), vascular disease, age 65-74 years, sex category; HAS-BLED, hypertension, abnormal renal/liver function, stroke, bleeding history or predisposition, labile INR, elderly, drugs/alcohol concomitantly; INR, international normalized ratio; PPIs, proton pump inhibitors.

Assessing Benefits and Long-term Effective ness) trial, which the present writing group endorses, is expected to yield additional information on optimal aspirin dosing in patients with atherosclerotic cardiovascular disease. ${ }^{83}$

\subsection{Triple Therapy (Aspirin, $P 2 Y_{12}$ Inhibitor, and Oral Anticoagulant)}

The recommended management of patients on "triple therapy" (aspirin, $\mathrm{P} 2 \mathrm{Y}_{12}$ inhibitor, and oral anticoagulant) is beyond the scope of this focused update. However, a brief discussion of the topic is included for the purposes of completeness and end-user education.

Compared with oral anticoagulation therapy alone, the addition of DAPT to oral anticoagulant therapy results in at least a 2- to 3-fold increase in bleeding complications. ${ }^{84-87}$ Discussion and recommendations on triple therapy are provided in the 2014 ACC/AHA NSTE-ACS guideline, ${ }^{14}$ a 2014 European joint consensus document, ${ }^{88}$ a North American consensus document, ${ }^{85}$ and several comprehensive state-of-the-art papers and reviews. A partial summary and synthesis of these recommendations are given in Table 6.

One trial comparing "double therapy" (oral anticoagulant plus clopidogrel) with triple therapy (oral anticoagulant plus aspirin and clopidogrel $)^{89}$ and 1 trial comparing differing durations of triple therapy have been published. ${ }^{90}$ Several more similar trials comparing oral anticoagulant therapy plus $\mathrm{P}_{2} \mathrm{Y}_{12}$ inhibitor with triple therapy are ongoing.

\section{PERCUTANEOUS CORONARY INTERVENTION 4.1. Duration of DAPT in Patients With SIHD Treated With PCI: Recommendations}

See Online Data Supplements 1 to 3 and 6 to 9 for evidence supporting these recommendations.
Recommendations for Duration of DAPT in Patients With SIHD Treated With PCI

\begin{tabular}{|c|c|c|}
\hline COR & LOE & Recommendations \\
\hline $\mathbf{I}$ & A & $\begin{array}{l}\text { In patients with SIHD treated with DAPT after } \\
\text { BMS implantation, } \mathrm{P} \mathrm{Y}_{12} \text { inhibitor therapy } \\
\text { (clopidogrel) should be given for a minimum } \\
\text { of } 1 \text { month. }{ }^{94,95}\end{array}$ \\
\hline I & B-R ${ }^{\text {SR }}$ & $\begin{array}{l}\text { In patients with SIHD treated with DAPT after } \\
\text { DES implantation, } \mathrm{P} \mathrm{Y}_{12} \text { inhibitor therapy } \\
\text { (clopidogrel) should be given for at least } \\
6 \text { months. }{ }^{17,18,21,30,96,97}\end{array}$ \\
\hline I & B-NR & $\begin{array}{l}\text { In patients treated with DAPT, a daily aspirin } \\
\text { dose of } 81 \mathrm{mg} \text { (range, } 75 \mathrm{mg} \text { to } 100 \mathrm{mg} \text { ) is } \\
\text { recommended. }{ }^{56-60,75-78}\end{array}$ \\
\hline Ilb & $A^{S R}$ & $\begin{array}{l}\text { In patients with SIHD treated with DAPT after } \\
\text { BMS or DES implantation who have tolerated } \\
\text { DAPT without a bleeding complication and who } \\
\text { are not at high bleeding risk (eg, prior bleeding } \\
\text { on DAPT, coagulopathy, oral anticoagulant use), } \\
\text { continuation of DAPT with clopidogrel for longer } \\
\text { than } 1 \text { month in patients treated with BMS or longer } \\
\text { than } 6 \text { months in patients treated with DES may be } \\
\text { reasonable. } \text {. }^{16,22,24-26,30,50}\end{array}$ \\
\hline Ilb & C-LD & 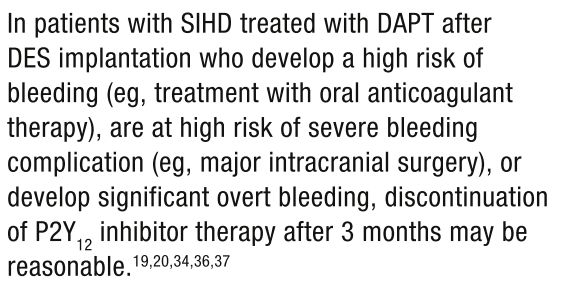 \\
\hline
\end{tabular}

$S R$, Systematic review.

\subsection{Duration of DAPT in Patients With ACS Treated With PCI: Recommendations}

See Online Data Supplements 1 to 9 for evidence supporting these recommendations.

Recommendations for Duration of DAPT in Patients With ACS Treated With PCI

\begin{tabular}{|c|c|c|}
\hline COR & LOE & Recommendations \\
\hline I & B-R & $\begin{array}{l}\text { In patients with ACS (NSTE-ACS or STEMI) treated } \\
\text { with DAPT after BMS or DES implantation, } \mathrm{P}^{2} \mathrm{Y}_{12} \\
\text { inhibitor therapy (clopidogrel, prasugrel, or ticagrelor) } \\
\text { should be given for at least } 12 \text { months. }{ }^{16,50-55,72,96-98}\end{array}$ \\
\hline I & B-NR & $\begin{array}{l}\text { In patients treated with DAPT, a daily aspirin } \\
\text { dose of } 81 \mathrm{mg} \text { (range, } 75 \mathrm{mg} \text { to } 100 \mathrm{mg} \text { ) is } \\
\text { recommended. }{ }^{56-60,75-78}\end{array}$ \\
\hline Ila & B-R & $\begin{array}{l}\text { In patients with ACS (NSTE-ACS or STEMI) } \\
\text { treated with DAPT after coronary stent implantation, } \\
\text { it is reasonable to use ticagrelor in preference } \\
\text { to clopidogrel for maintenance } \mathrm{P}_{2} \mathrm{Y}_{12} \text { inhibitor } \\
\text { therapy. }{ }^{53,72}\end{array}$ \\
\hline
\end{tabular}


Recommendations for Duration of DAPT in Patients With ACS Treated With PCI (Continued)

\begin{tabular}{|c|c|c|}
\hline COR & LOE & Recommendations \\
\hline Ila & B-R & $\begin{array}{l}\text { In patients with ACS (NSTE-ACS or STEMI) treated } \\
\text { with DAPT after coronary stent implantation who are } \\
\text { not at high risk for bleeding complications and who } \\
\text { do not have a history of stroke or TIA, it is reasonable } \\
\text { to choose prasugrel over clopidogrel for maintenance } \\
\text { P2Y }{ }_{12} \text { inhibitor therapy. }{ }^{54,55}\end{array}$ \\
\hline Ilb & $A^{S R}$ & $\begin{array}{l}\text { In patients with ACS (NSTE-ACS or STEMI) treated } \\
\text { with coronary stent implantation who have tolerated } \\
\text { DAPT without a bleeding complication and who } \\
\text { are not at high bleeding risk (eg, prior bleeding } \\
\text { on DAPT, coagulopathy, oral anticoagulant use), } \\
\text { continuation of DAPT (clopidogrel, prasugrel, or } \\
\text { ticagrelor) for longer than } 12 \text { months may be } \\
\text { reasonable. }{ }^{16,22-26,28,30,40,41,43,53,54,72}\end{array}$ \\
\hline Ilb & C-LD & $\begin{array}{l}\text { In patients with ACS treated with DAPT after DES } \\
\text { implantation who develop a high risk of bleeding } \\
\text { (eg, treatment with oral anticoagulant therapy), are } \\
\text { at high risk of severe bleeding complication (eg, } \\
\text { major intracranial surgery), or develop significant } \\
\text { overt bleeding, discontinuation of } \mathrm{P}_{2} \mathrm{Y}_{12} \text { inhibitor } \\
\text { therapy after } 6 \text { months may be reasonable. }{ }^{17-21,34,36,37}\end{array}$ \\
\hline : Harm & B-R & $\begin{array}{l}\text { Prasugrel should not be administered to patients with } \\
\text { a prior history of stroke or TIA. }{ }^{54}\end{array}$ \\
\hline
\end{tabular}

$S R$, Systematic review.

\subsection{Duration of DAPT in Patients With SIHD and ACS Treated With PCI}

DAPT in patients treated with coronary stent implantation reduces the risk of stent thrombosis and ischemic events $^{50,51,94,95,99}$ (Data Supplement 7). The risk of stent thrombosis in patients treated with a bare metal stent (BMS) is greatest in the first days to weeks after implantation. ${ }^{99,100}$ Cessation of DAPT during this period, particularly in cases of patients undergoing surgery, is associated with an unacceptable rate of often catastrophic stent thrombosis. ${ }^{101-103}$ Thus, a minimum duration of DAPT of 1 month is generally recommended for patients treated with BMS. In current practice, BMS are generally reserved for patients who cannot receive DAPT for more than $\approx 1$ month for reasons of active bleeding, nonadherence to medical therapy, or planned surgery.

The recommended minimum duration of DAPT in patients treated with first-generation DES, based primarily on observational data and one subgroup analysis, has been 12 months. $^{9,51,97,104,105}$ Compared with first-generation DES, currently used newer-generation DES have a lower risk of stent thrombosis and appear to require a shorter minimum duration of DAPT. ${ }^{17,18,21,38,96,97}$ Five RCTs ${ }^{17-21}$ of primarily low-risk (non-ACS) patients treated with DES comparing shorter-duration (3 to 6 months) DAPT with 12 months of DAPT, as well as several meta-analyses ${ }^{34-37}$ and an analysis by the ERC, ${ }^{30}$ did not find an increased risk of stent thrombosis with shorter-duration DAPT, although the individual trials were underpowered to detect such a difference (Data Supplements 1 and 3). Therefore, in patients with SIHD treated with DES, the minimum recommended duration of DAPT has been decreased from 12 to 6 months.

The PCI-CURE analysis ${ }^{51}$ of patients in the CURE (Clopidogrel in Unstable Angina to Prevent Recurrent Events) trial $^{52}$ demonstrated that treatment with DAPT for up to 12 months in patients with NSTE-ACS treated with BMS reduced ischemic events compared with aspirin monotherapy (Data Supplement 4). Based primarily on the CURE trial and PCI-CURE analyses, the prior recommendation that patients with NSTE-ACS treated with coronary stent implantation be treated with DAPT for at least 12 months is continued in this update and has been extrapolated to patients with STEMI treated with PCI as well, on the basis of the consideration that NSTE-ACS and STEMI are part of the spectrum of ACS.

As detailed in Section 2, treatment with prolonged (or "extended") DAPT beyond a minimum recommended duration of therapy necessitates a fundamental tradeoff between decreasing ischemic risk (eg, MI and stent thrombosis) and increasing bleeding risk. ${ }^{16,30,34,36,37,46}$ Prolonged or extended DAPT for an additional 18 to 36 months (after an initial 6 to 12 months of DAPT) in patients treated with DES implantation results in an absolute decrease in stent thrombosis and ischemic complications of $\approx 1 \%$ to $2 \%$ and an absolute increase in bleeding complications of $\approx 1 \%$ (Data Supplements 1,2 , and 3). ${ }^{16,22-27,30,35-37,46}$ Newer-generation stents, particularly everolimus-eluting stents, are associated with lower rates of stent thrombosis, and the absolute reduction in the rate of stent thrombosis with prolonged DAPT in patients treated with everolimus-eluting stents is modest. ${ }^{39,106-109}$

The benefit/risk ratio of prolonged DAPT in patients treated with PCI may be more favorable for those with prior MI (or ACS) than for those with SIHD. ${ }^{28,41,43}$ Preliminary data suggest that in patients with a high DAPT score the benefit/risk ratio with prolonged DAPT may be favorable and that in those with a low DAPT score the benefit/risk ratio with prolonged DAPT is not favorable. ${ }^{61}$ In patients treated with coronary stent implantation who have increased bleeding risk (eg, oral anticoagulation), increased risk of severe bleeding complications (eg, major intracranial surgery), or significant overt bleeding, the benefit/risk ratio may favor shorter-thanrecommended duration of DAPT. ${ }^{17-21,34,36}$ Decisions about treatment with and duration of DAPT require a thoughtful assessment of the benefit/risk ratio, 


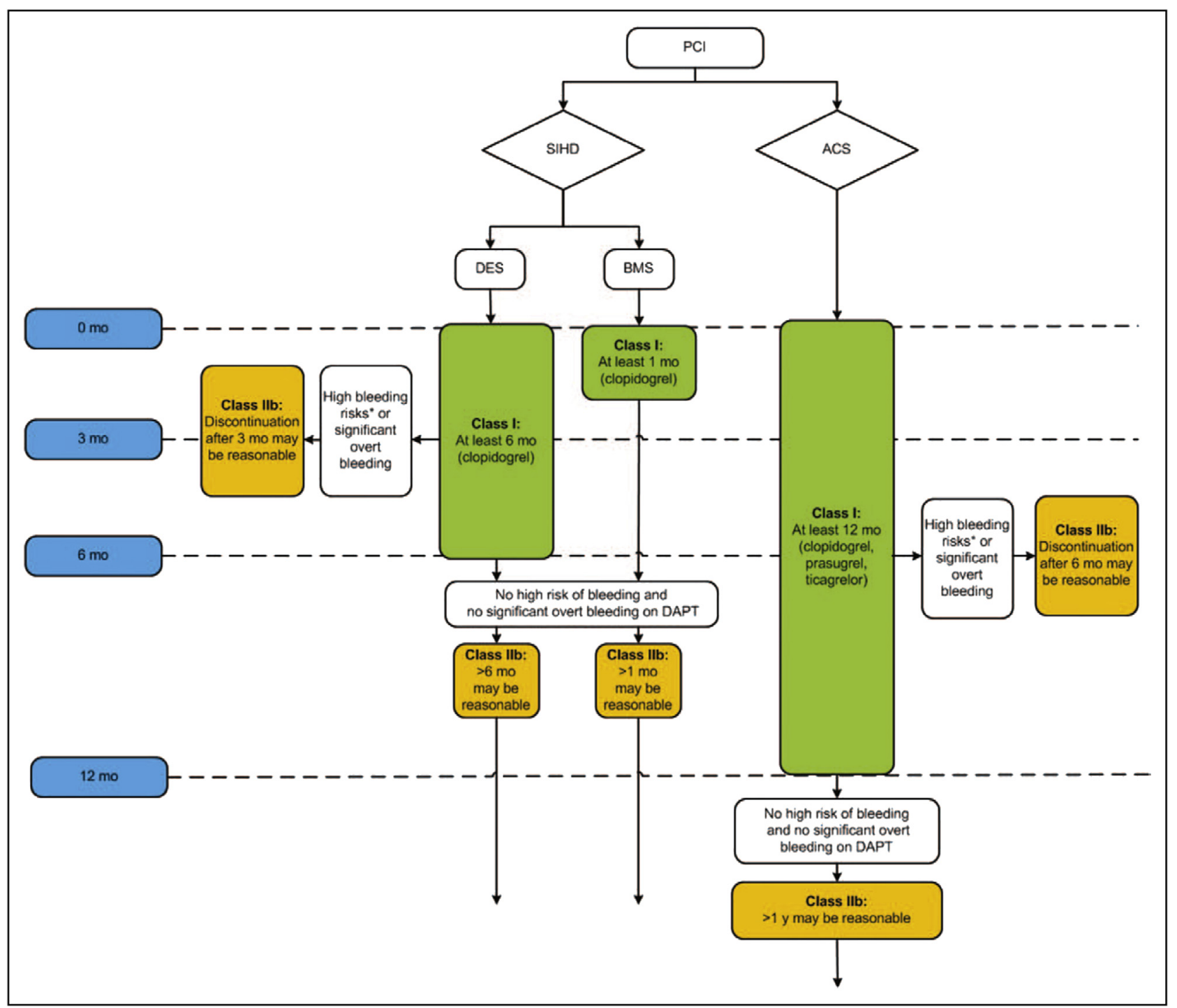

FIGURE 2. Treatment algorithm for duration of $\mathrm{P} 2 \mathrm{Y}_{12}$ inhibitor therapy in patients treated with PCI. Colors correspond to Class of Recommendation in Table 1. Arrows at the bottom of the figure denote that the optimal duration of prolonged DAPT is not established. Clopidogrel is the only currently used $\mathrm{P}_{2} \mathrm{Y}_{12}$ inhibitor studied in patients with SIHD undergoing PCI. Aspirin therapy is almost always continued indefinitely in patients with coronary artery disease. *High bleeding risk denotes those who have or develop a high risk of bleeding (eg, treatment with oral anticoagulant therapy) or are at increased risk of severe bleeding complication (eg, major intracranial surgery). PCI, Percutaneous coronary intervention; SIHD, stable ischemic heart disease; ACS, acute coronary syndrome; $D E S$, drug-eluting stent; $B M S$, bare metal stent; $D A P T$, dual antiplatelet therapy.

integration of current and future study data, and consideration of patient preference.

In studies of drug-eluting bioabsorbable polymer stents and bioabsorbable stents (third- and fourth-generation stents), by study protocol, DAPT was continued for at least 6 to 12 months. ${ }^{10-116}$ In a study of a novel polymer-free and carrierfree drug-coated stent in patients at high risk of bleeding complications, by study protocol, DAPT was continued for only 1 month. ${ }^{117}$ These stents have not been included in the studies of shorter- or longer-duration (prolonged/extended) DAPT discussed in this focused update. Because none of these stents (except one biodegradable polymer DES) was approved by the US Food and Drug Administration at the time this focused update was written, recommendations for duration of DAPT for such stents are not included.

Recommendations for duration of DAPT in patients treated with PCI are summarized in Figure 2.

\section{RECOMMENDATIONS FOR DURATION OF DAPT IN PATIENTS UNDERGOING CABG}

See Online Data Supplements 4, 6, 10, and 11 for evidence supporting these recommendations. 
Recommendations for Duration of DAPT in Patients Undergoing CABG

\begin{tabular}{|c|c|l|}
\hline COR & LOE & Recommendations \\
\hline I & C-EO & $\begin{array}{l}\text { In patients treated with DAPT after coronary stent } \\
\text { implantation who subsequently undergo CABG, P2Y } \\
\text { inhibitor therapy should be resumed postoperatively s0 } \\
\text { that DAPT continues until the recommended duration } \\
\text { of therapy is completed. }\end{array}$ \\
\hline I & C-LD & $\begin{array}{l}\text { In patients with ACS (NSTE-ACS or STEMI) } \\
\text { being treated with DAPT who undergo CABG, P2Y } \\
\text { inhibitor therapy should be resumed after CABG } \\
\text { to complete 12 months of DAPT therapy after } \\
\text { ACS.52-54,118-120 }\end{array}$ \\
\hline I & B-NR & $\begin{array}{l}\text { In patients treated with DAPT, a daily aspirin } \\
\text { dose of } 81 \text { mg (range, } 75 \text { mg to } 100 \text { mg) is } \\
\text { recommended. }{ }^{56-60,75-78}\end{array}$ \\
\hline Ilb & B-NR & $\begin{array}{l}\text { In patients with SIHD, DAPT (with clopidogrel } \\
\text { initiated early postoperatively) for 12 months after } \\
\text { CABG may be reasonable to improve vein graft } \\
\text { patency. }{ }^{121-125}\end{array}$ \\
\hline
\end{tabular}

Aspirin therapy after CABG improves vein graft patency, particularly during the first postoperative year, and reduces MACE. ${ }^{126-130}$ In the CURE study, ${ }^{52}$ the reduction in ischemic events in patients treated with aspirin plus clopidogrel who underwent $\mathrm{CABG}$ was consistent with the study population as a whole, although benefit was primarily observed mainly before the procedure. ${ }^{118}$ A propensity score analysis of a Danish administrative database $\mathrm{e}^{120}$ demonstrated during a mean follow-up of $466 \pm 144$ days significantly fewer deaths in patients treated with aspirin plus clopidogrel than in those treated with aspirin alone, although there was no reduction in the incidence of recurrent MI.

The impact of clopidogrel on graft occlusion after onpump CABG has been evaluated in 5 studies (Data Supplement 10). Several randomized and nonrandomized trials and a post hoc substudy analysis of patients predominantly undergoing on-pump CABG did not demonstrate any differences in graft patency between antiplatelet monotherapy and DAPT when assessed at follow-up ranging from 1 month to 1 year after CABG. ${ }^{131-134}$ In the only RCT to demonstrate a benefit of DAPT, vein graft patency 3 months after CABG was significantly higher in patients treated with clopidogrel and aspirin $(100 \mathrm{mg})$ than in those receiving aspirin monotherapy. ${ }^{121}$

Two meta-analyses and 1 systematic overview assessed the potential benefits of DAPT after CABG and reported mixed results ${ }^{122,123,135}$ (Data Supplement 10). In the largest meta-analysis of patients pooled from 5 RCTs and 6 observational studies, ${ }^{122}$ DAPT was associated with reduced vein graft occlusion and 30-day mortality rate as compared with aspirin monotherapy. A meta-analysis of only the $5 \mathrm{RCTs}^{123}$ showed that DAPT was associated with a significantly lower vein graft occlusion at 1 year versus antiplatelet monotherapy but with no improvement in arterial graft patency. Major bleeding after surgery was more frequent with DAPT. ${ }^{122,123,135}$

The benefits of DAPT in off-pump CABG patients were noted in terms of improved graft patency ${ }^{124,125}$ and clinical outcome ${ }^{136}$ in single-center observational studies ${ }^{124,136}$ and an $\mathrm{RCT}^{125}$ (Data Supplement 10).

Only data from post hoc analyses are available on the utility of newer $\mathrm{P}_{2} \mathrm{Y}_{12}$ inhibitors in patients with ACS who undergo CABG. In a retrospective analysis of patients in the TRITON-TIMI 38 study $^{54}$ who underwent CABG, ${ }^{137}$ prasugrel treatment was associated with a significantly lower 30-day mortality rate than that of clopidogrel and more postoperative blood loss. A post hoc analysis of patients who underwent CABG in the PLATO study ${ }^{53}$ showed that the primary endpoint at 1 year was similar for both treatments, but a significant reduction in cardiovascular mortality was noted with ticagrelor compared with clopidogrel. ${ }^{138,139}$

Issues related to the timing of discontinuation of DAPT before CABG are beyond the scope of this update but are addressed in the 2011 CABG guideline. ${ }^{10}$ Figure 3 summarizes recommendations for the management and duration of $\mathrm{P}_{2} \mathrm{Y}_{12}$ inhibitor therapy in patients undergoing CABG.

\section{RECOMMENDATIONS FOR DURATION OF DAPT IN PATIENTS WITH SIHD}

See Online Data Supplements 1 to 4 and 6 to 11 for evidence supporting these recommendations.

Recommendations for Duration of DAPT in Patients With SIHD

\begin{tabular}{|c|c|c|}
\hline COR & LOE & Recommendations \\
\hline I & A & $\begin{array}{l}\text { In patients with SIHD treated with DAPT after BMS } \\
\text { implantation, } \mathrm{P}_{2 Y_{12}} \text { inhibitor therapy (clopidogrel) } \\
\text { should be given for a minimum of } 1 \text { month. }{ }^{94,95}\end{array}$ \\
\hline I & B-R SR & $\begin{array}{l}\text { In patients with SIHD treated with DAPT after DES } \\
\text { implantation, } \mathrm{P}_{2} \mathrm{Y}_{12} \text { inhibitor therapy (clopidogrel) } \\
\text { should be given for at least } 6 \text { months. }{ }^{17,18,21,30,96,97}\end{array}$ \\
\hline I & B-NR & $\begin{array}{l}\text { In patients treated with DAPT, a daily aspirin } \\
\text { dose of } 81 \mathrm{mg} \text { (range, } 75 \mathrm{mg} \text { to } 100 \mathrm{mg} \text { ) is } \\
\text { recommended. }\end{array}$ \\
\hline Ilb & $A^{S R}$ & $\begin{array}{l}\text { In patients with SIHD being treated with DAPT for } \\
\text { an MI that occurred } 1 \text { to } 3 \text { years earlier who have } \\
\text { tolerated DAPT without a bleeding complication } \\
\text { and who are not at high bleeding risk (eg, prior } \\
\text { bleeding on DAPT, coagulopathy, oral anticoagulant } \\
\text { use), further continuation of DAPT may be } \\
\text { reasonable. }\end{array}$ \\
\hline
\end{tabular}


Recommendations for Duration of DAPT in Patients With SIHD (Continued)

\begin{tabular}{|c|c|c|}
\hline COR & LOE & Recommendations \\
\hline Ilb & $A^{\mathrm{SR}}$ & $\begin{array}{l}\text { In patients with SIHD treated with BMS or DES } \\
\text { implantation who have tolerated DAPT without } \\
\text { a bleeding complication and who are not at } \\
\text { high bleeding risk (eg, prior bleeding on DAPT, } \\
\text { coagulopathy, oral anticoagulant use), continuation } \\
\text { of DAPT with clopidogrel for longer than } 1 \text { month } \\
\text { in patients treated with BMS or longer than } 6 \\
\text { months in patients treated with DES may be } \\
\text { reasonable. }{ }^{16,22,24-26,30,50}\end{array}$ \\
\hline Ilb & C-LD & $\begin{array}{l}\text { In patients with SIHD treated with DAPT after DES } \\
\text { implantation who develop a high risk of bleeding (eg, } \\
\text { treatment with oral anticoagulant therapy), are at } \\
\text { high risk of severe bleeding complication (eg, major } \\
\text { intracranial surgery), or develop significant overt } \\
\text { bleeding, discontinuation of P2Y } \text { inhibitor therapy }_{12} \\
\text { after } 3 \text { months may be reasonable. }{ }^{19,20,34,36,37}\end{array}$ \\
\hline Ilb & B-NR & $\begin{array}{l}\text { In patients with SIHD, treatment with DAPT (with } \\
\text { clopidogrel initiated early postoperatively) for } 12 \\
\text { months after CABG may be reasonable to improve } \\
\text { vein graft patency. }{ }^{121-125}\end{array}$ \\
\hline $\begin{array}{l}\text { III: No } \\
\text { Benefit }\end{array}$ & B-R & $\begin{array}{l}\text { In patients with SIHD without prior history of ACS, } \\
\text { coronary stent implantation, or recent (within } \\
12 \text { months) CABG, treatment with DAPT is not } \\
\text { beneficial. }{ }^{28,40-42}\end{array}$ \\
\hline
\end{tabular}

For the purposes of this update, patients with a history of ACS $>1$ year prior who have remained free of recurrent ACS are considered to have transitioned to SIHD.

In the CHARISMA trial, which randomized patients with established atherosclerosis or at high risk of clinical atherosclerotic disease to either DAPT (with clopidogrel) or aspirin monotherapy, no significant reduction was found in ischemic effects at a median follow-up of 28 months with DAPT, but a $0.4 \%$ absolute increase was seen in severe bleeding. ${ }^{40}$ In a post hoc analysis of patients enrolled in the study with prior MI, a $1.7 \%$ absolute decrease in the composite endpoint of cardiovascular death, MI, or stroke events was observed with DAPT, but no benefit was seen in those with CAD without prior MI (Data Supplement 4). ${ }^{40,41}$ In the PEGASUS-TIMI 54 trial, in which stable patients 1 to 3 years after MI with additional high-risk features were randomized to either DAPT (with ticagrelor $60 \mathrm{mg}$ or $90 \mathrm{mg}$ twice daily) or continued aspirin monotherapy, a mean of 33 months of DAPT led to a $1.2 \%$ to $1.3 \%$ absolute reduction in ischemic events and a $1.2 \%$ to $1.5 \%$ increase in major bleeding. ${ }^{28}$ In subgroup analysis, the greatest reduction in ischemic events was in patients in whom P2 $Y_{12}$ inhibitor therapy either had not been discontinued or had been discontinued $\leq 30$ days before enrollment in

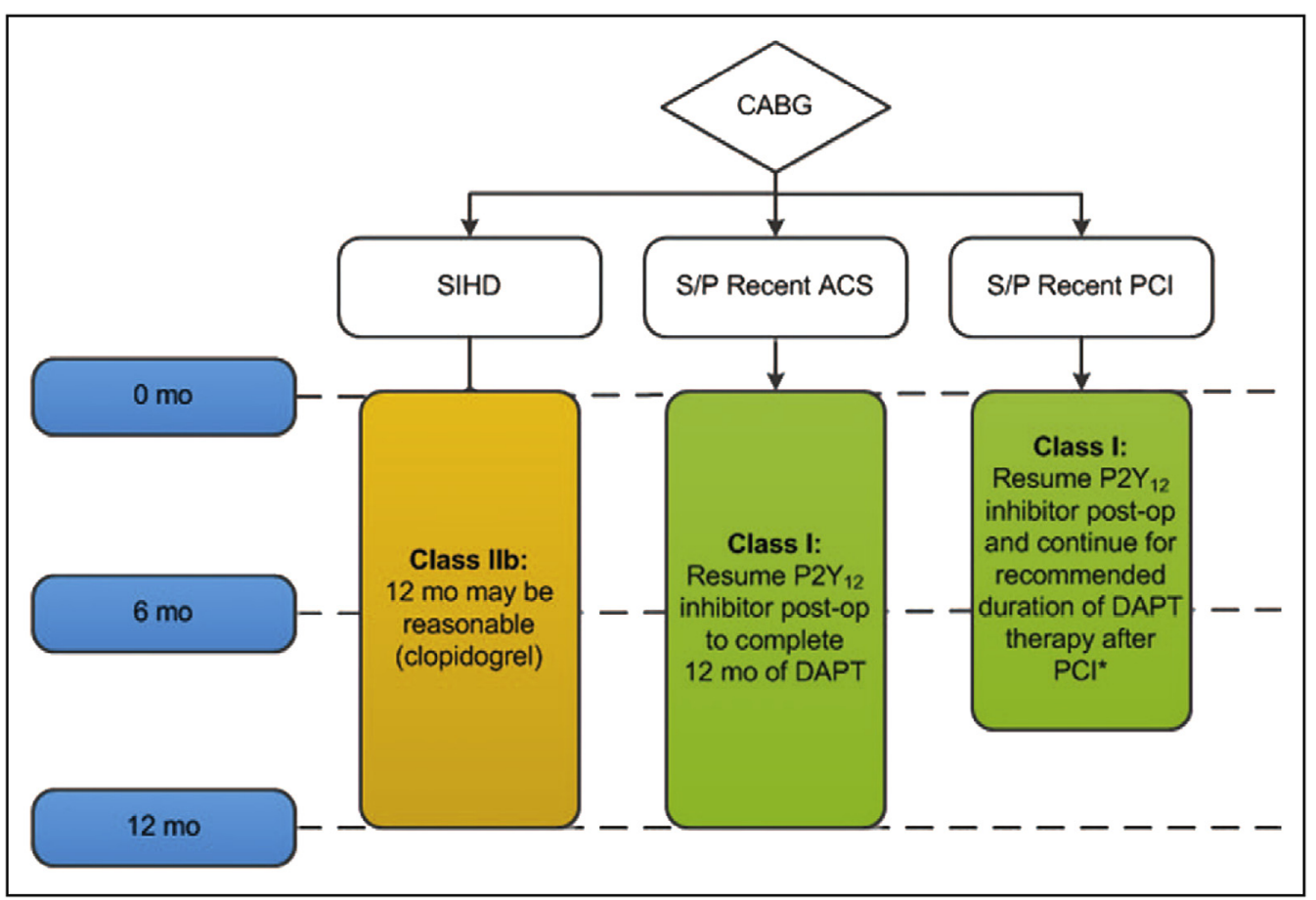

FIGURE 3. Treatment algorithm for management and duration of $\mathrm{P} 2 \mathrm{Y}_{12}$ inhibitor therapy in patients undergoing CABG. Colors correspond to Class of Recommendation in Table 1 . Aspirin therapy is almost always continued indefinitely in patients with coronary artery disease. *Duration of DAPT therapy can vary from as little as 4 weeks to $>12$ months, depending on the clinical setting and bleeding risk. $C A B G$, Coronary artery bypass graft surgery; SIHD, stable ischemic heart disease; $S / P$, status post; $A C S$, acute coronary syndrome; $P C I$, percutaneous coronary intervention; post-op, postoperatively; DAPT, dual antiplatelet therapy. 
the study (absolute reduction in MACE: $1.9 \%$ to $2.5 \%$ ), and no benefit was seen in patients in whom $\mathrm{P}_{2} \mathrm{Y}_{12}$ inhibitor therapy had been discontinued $>1$ year before enrollment in the study. ${ }^{42}$ On the basis of all studies of DAPT in post-MI patients, extended DAPT for approximately 18 to 36 months leads to an absolute decrease in ischemic complications of $\approx 1 \%$ to $3 \%$ and an absolute increase in bleeding complications of $\approx 1 \%$ (Data Supplement 4). ${ }^{28,40,41,43,44}$

DAPT is not recommended in patients with SIHD without prior stent implantation and no history of ACS or MI. Decisions about treatment with and duration of DAPT in patients with SIHD with a history of MI or coronary stent implantation require a thoughtful assessment of the benefit/risk ratio, integration of study data, and consideration of patient preference.

Figure 4 summarizes recommendations on duration of P2 $\mathrm{Y}_{12}$ inhibitor therapy in patients with SIHD.

\section{ACUTE CORONARY SYNDROME (NSTE-ACS AND STEMI)}

\subsection{Duration of DAPT in Patients With ACS Treated With Medical Therapy Alone (Without \\ Revascularization or Fibrinolytic Therapy): \\ Recommendations}

See Online Data Supplements 4 to 6 for evidence supporting these recommendations.

Recommendations for Duration of DAPT in Patients With ACS Treated with Medical Therapy Alone

\begin{tabular}{|c|c|c|}
\hline COR & LOE & Recommendations \\
\hline I & B-R & $\begin{array}{l}\text { In patients with ACS who are managed with medical } \\
\text { therapy alone (without revascularization or fibrinolytic } \\
\text { therapy) and treated with DAPT, } \mathrm{P}_{12} \text { inhibitor therapy } \\
\text { (clopidogrel or ticagrelor) should be continued for at } \\
\text { least } 12 \text { months. }{ }^{52,71,140,141}\end{array}$ \\
\hline I & B-NR & $\begin{array}{l}\text { In patients treated with DAPT, a daily aspirin dose of } 81 \\
\mathrm{mg} \text { (range, } 75 \mathrm{mg} \text { to } 100 \mathrm{mg} \text { ) is recommended. }{ }^{56-60,75-78}\end{array}$ \\
\hline Ila & B-R & $\begin{array}{l}\text { In patients with NSTE-ACS who are managed with } \\
\text { medical therapy alone (without revascularization or } \\
\text { fibrinolytic therapy) and treated with DAPT, it is } \\
\text { reasonable to use ticagrelor in preference to } \\
\text { clopidogrel for maintenance } \mathrm{P} \mathrm{Y}_{12} \text { inhibitor therapy. }{ }^{53,71}\end{array}$ \\
\hline Ilb & $A^{S R}$ & $\begin{array}{l}\text { In patients with ACS treated with medical therapy } \\
\text { alone (without revascularization or fibrinolytic } \\
\text { therapy) who have tolerated DAPT without bleeding } \\
\text { complication and who are not at high bleeding risk } \\
\text { (eg, prior bleeding on DAPT, coagulopathy, oral } \\
\text { anticoagulant use), continuation of DAPT for longer } \\
\text { than } 12 \text { months may be reasonable. }{ }^{28,30,40,41,43,53,71,141}\end{array}$ \\
\hline
\end{tabular}

$S R$, Systematic review.

\subsection{Duration of DAPT in Patients With STEMI Treated With Fibrinolytic Therapy: Recommendations}

See Online Data Supplements 4 and 6 for evidence supporting these recommendations.

Recommendations for Duration of DAPT in Patients With STEMI Treated With Fibrinolytic Therapy

\begin{tabular}{|c|c|c|}
\hline COR & LOE & Recommendations \\
\hline \multirow{2}{*}{ I } & A & $\begin{array}{l}\text { In patients with STEMI treated with DAPT in } \\
\text { conjunction with fibrinolytic therapy, } \mathrm{P}_{12} \text { inhibitor }\end{array}$ \\
\hline & C-EO & $\begin{array}{l}\text { minimum of } 14 \text { days (Level of Evidence: A) })^{140,142} \text { and } \\
\text { ideally at least } 12 \text { months (Level of Evidence: } C \text {-EO). }\end{array}$ \\
\hline I & B-NR & $\begin{array}{l}\text { In patients treated with DAPT, a daily aspirin dose of } 81 \\
\mathrm{mg} \text { (range, } 75 \mathrm{mg} \text { to } 100 \mathrm{mg} \text { ) is recommended. }{ }^{56-60,75-78}\end{array}$ \\
\hline Illb & $A^{S R}$ & $\begin{array}{l}\text { In patients with STEMI treated with fibrinolytic therapy } \\
\text { who have tolerated DAPT without bleeding complication } \\
\text { and who are not at high bleeding risk (eg, prior bleeding } \\
\text { on DAPT, coagulopathy, oral anticoagulant use), } \\
\text { continuation of DAPT for longer than } 12 \text { months may be } \\
\text { reasonable. } 16,22-26,28,30,40,41,43,53,54,71,72,141\end{array}$ \\
\hline
\end{tabular}

$S R$, Systematic review.

\subsection{Duration of DAPT in Patients With ACS Treated With PCI: Recommendations}

See Online Data Supplements 1 to 9 for evidence supporting these recommendations.

Recommendations for Duration of DAPT in Patients With ACS Treated With PCI

\begin{tabular}{|c|c|c|}
\hline COR & LOE & Recommendations \\
\hline I & B-R & $\begin{array}{l}\text { In patients with ACS treated with DAPT after BMS or } \\
\text { DES implantation, } \mathrm{P} 2 \mathrm{Y}_{12} \text { inhibitor therapy (clopidogrel, } \\
\text { prasugrel, or ticagrelor) should be given for at least } 12 \\
\text { months. }{ }^{16,50-55,72,96-98}\end{array}$ \\
\hline I & B-NR & $\begin{array}{l}\text { In patients treated with DAPT, a daily aspirin } \\
\text { dose of } 81 \mathrm{mg} \text { (range, } 75 \mathrm{mg} \text { to } 100 \mathrm{mg} \text { ) is } \\
\text { recommended. }{ }^{56-60,75-78}\end{array}$ \\
\hline Ila & B-R & $\begin{array}{l}\text { In patients with ACS treated with DAPT after coronary stent } \\
\text { implantation, it is reasonable to use ticagrelor in preference } \\
\text { to clopidogrel for maintenance } P 2 Y_{12} \text { inhibitor therapy. } .^{53,72}\end{array}$ \\
\hline Ila & B-R & $\begin{array}{l}\text { In patients with ACS treated with DAPT after coronary } \\
\text { stent implantation, who are not at high risk for bleeding } \\
\text { complications and who do not have a history of stroke or } \\
\text { TIA, it is reasonable to choose prasugrel over clopidogrel } \\
\text { for maintenance } P 2 Y_{12} \text { inhibitor therapy. } \text {. }^{4,55}\end{array}$ \\
\hline
\end{tabular}


Recommendations for Duration of DAPT in Patients With ACS Treated With PCI (Continued)

\begin{tabular}{|c|c|c|}
\hline COR & LOE & Recommendations \\
\hline Ilb & $A^{S R}$ & $\begin{array}{l}\text { In patients with ACS treated with coronary stent } \\
\text { implantation who have tolerated DAPT without } \\
\text { bleeding complication and who are not at high } \\
\text { bleeding risk (eg, prior bleeding on DAPT, } \\
\text { coagulopathy, oral anticoagulant use) continuation } \\
\text { of DAPT for longer than } 12 \text { months may be } \\
\text { reasonable. }{ }^{16,22-26,28,30,40,41,43,53,54,72}\end{array}$ \\
\hline Ilb & C-LD & $\begin{array}{l}\text { In patients with ACS treated with DAPT after DES } \\
\text { implantation who develop a high risk of bleeding (eg, } \\
\text { treatment with oral anticoagulant therapy), are at } \\
\text { high risk of severe bleeding complication (eg, major } \\
\text { intracranial surgery), or develop significant overt } \\
\text { bleeding, discontinuation of P2Y } Y_{12} \text { therapy after } 6 \\
\text { months may be reasonable. }{ }^{17-21,34,36,37}\end{array}$ \\
\hline l: Harm & B-R & $\begin{array}{l}\text { Prasugrel should not be administered to patients with } \\
\text { a prior history of stroke or TIA. }{ }^{54}\end{array}$ \\
\hline
\end{tabular}

$S R$, Systematic review.

\subsection{Duration of DAPT in Patients With ACS Treated With CABG: Recommendation}

See Online Data Supplement 4 and 11 for evidence supporting this recommendation.

Recommendation for Duration of DAPT in Patients With ACS Treated With CABG

\begin{tabular}{|c|c|l|}
\hline COR & LOE & Recommendation \\
\hline I & C-LD & $\begin{array}{l}\text { In patients with ACS being treated with DAPT who } \\
\text { undergo CABG, P2Y } \\
\text { resumed after CABG to complete 12 months of DAPT } \\
\text { therapy after ACS. } \text {.2-54,118-120 }^{5}\end{array}$ \\
\hline
\end{tabular}

\subsection{Duration of DAPT in Patients With ACS}

Aspirin remains the cornerstone of antiplatelet therapy in patients with ACS. Further platelet inhibition, with an associated reduction in ischemic risk, can be achieved by blocking the $\mathrm{P}_{2} \mathrm{Y}_{12}$ receptor. In the CURE trial of patients with NSTE-ACS, the addition of clopidogrel (for up to 1 year) to aspirin monotherapy resulted in a $2.1 \%$ absolute reduction in subsequent ischemic events but also a $1.0 \%$ absolute increase in major bleeding. ${ }^{52}$ The majority of patients in this study were treated without revascularization, though benefit was observed both in those treated with revascularization (PCI or CABG) and in those treated with medical therapy alone. ${ }^{51,52}$ Available evidence from this trial, as well as from PLATO ${ }^{53,71,72}$ and TRITON-TIMI 38, ${ }^{54,55}$ supports DAPT duration of at least 12 months for patients with NSTE-ACS.
The results of the CURE trial ${ }^{52}$ and PCI-CURE analyses of the CURE trial ${ }^{51}$ (Data Supplement 4) have been extrapolated to patients with STEMI on the basis of the consideration that NSTE-ACS and STEMI are both part of the spectrum of ACS and usually caused by coronary plaque rupture. Based on this consideration, as well as the results from the PLATO and TRITON-TIMI 38 trials, it is recommended that patients with STEMI treated with coronary stent implantation or medical therapy alone (without revascularization or reperfusion therapy) be treated with DAPT for at least 12 months. ${ }^{53-55,71,72}$ Ticagrelor is considered a $\mathrm{P}_{2} \mathrm{Y}_{12}$ treatment option in patients with STEMI not treated with revascularization (or reperfusion therapy) on the basis of a similar extrapolation of the results of the "medically managed" patients with ACS in the PLATO trial. ${ }^{71}$ On the basis of CURE, PCI-CURE, PLATO, and TRITONTIMI 38, clopidogrel, prasugrel, and ticagrelor are all $\mathrm{P} \mathrm{Y}_{12}$ treatment options in patients with ACS treated with PCI.

In the CLARITY-TIMI 28 (Clopidogrel as Adjunctive Reperfusion Therapy-Thrombolysis In Myocardial Infarction 28) trial, short-term treatment (up to 8 days) with clopidogrel (in addition to aspirin) in patients with STEMI undergoing fibrinolytic therapy improved TIMI flow grade in the culprit artery and decreased the composite endpoint of cardiovascular death, reinfarction, or the need for urgent revascularization. ${ }^{142}$ In COMMIT (Clopidogrel and Metoprolol in Myocardial Infarction Trial) (93\% with STEMI not managed with primary PCI), treatment for $\approx 2$ weeks with clopidogrel (in addition to aspirin $162 \mathrm{mg}$ ) resulted in a $0.9 \%$ absolute reduction of the 28-day composite endpoint of death, reinfarction, or stroke and a $0.6 \%$ absolute reduction in death. ${ }^{140} \mathrm{~A} 1.1 \%$ absolute risk reduction in the composite endpoint was seen in the subgroup of patients who received fibrinolytic therapy. On the basis of these trials and extrapolation of the results of CURE, DAPT with aspirin and clopidogrel is recommended for a minimum of 14 days and ideally at least 12 months in patients with STEMI treated with fibrinolytic therapy (Data Supplement 4).

As discussed in Section 3, treatment with prolonged (extended) DAPT beyond a minimum recommended duration necessitates a fundamental tradeoff between decreasing ischemic risk (eg, MI and stent thrombosis) and increasing bleeding risk. . $^{16,24,28,30,34,36,37,46}$ In postMI patients, extended DAPT for approximately 18 to 36 months leads to an absolute decrease in ischemic complications of $\approx 1 \%$ to $3 \%$ and an absolute increase in bleeding complications of $\approx 1 \%$ (Data Supplement 4). ${ }^{28,40,41,43,44}$ An analysis from the PEGASUS-TIMI 54 trial found that the greatest reduction in ischemic events with prolonged DAPT in 


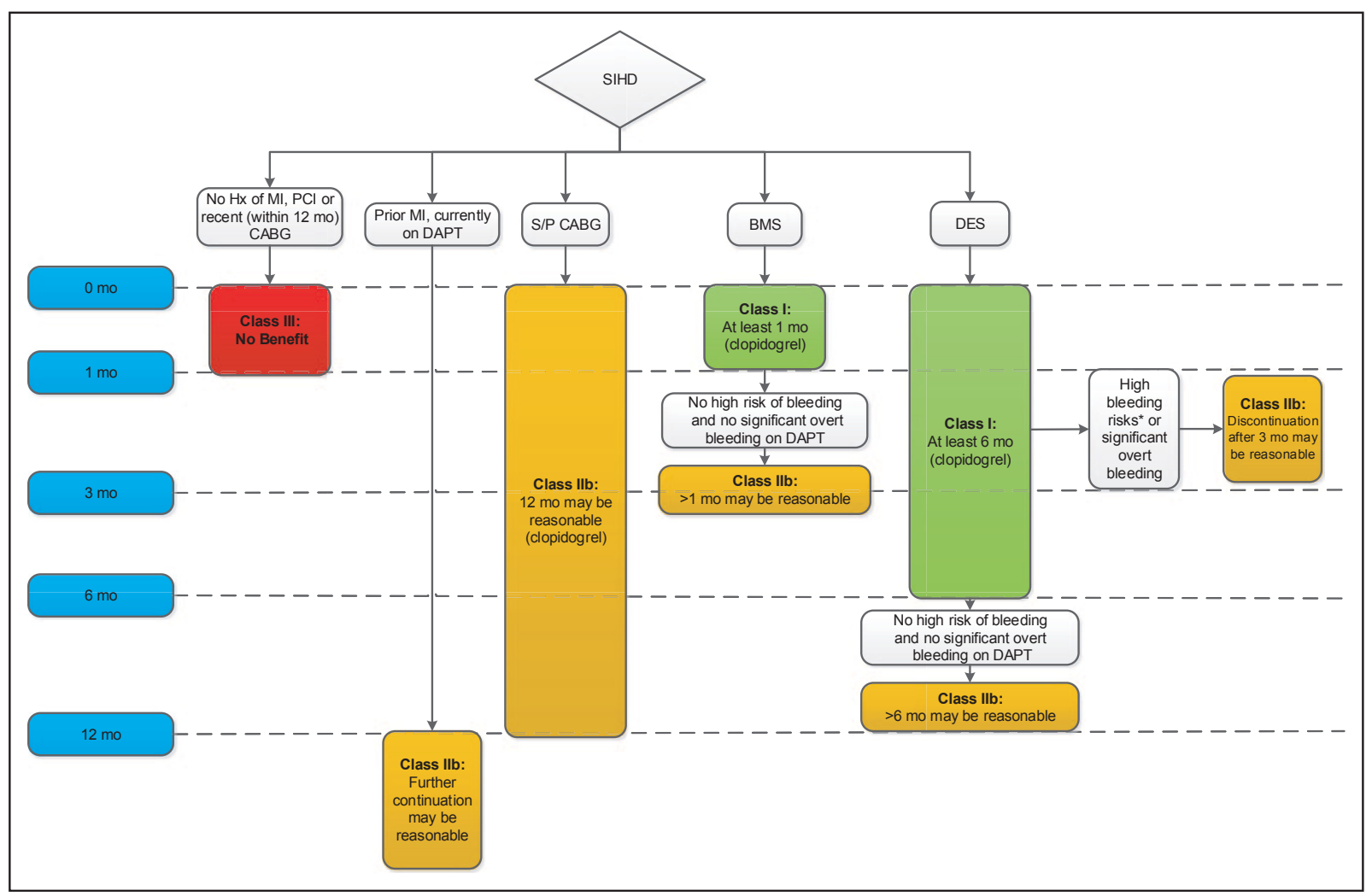

FIGURE 4. Treatment algorithm for duration of $\mathrm{P} 2 \mathrm{Y}_{12}$ inhibitor therapy in patients with SIHD (without ACS within the past several years). Colors correspond to Class of Recommendation in Table 1. Patients with a history of ACS $>1$ year prior who have since remained free of recurrent ACS are considered to have transitioned to SIHD. Arrows at the bottom of the figure denote that the optimal duration of prolonged DAPT is not established. Clopidogrel is the only currently used P2 $\mathrm{Y}_{12}$ inhibitor studied in patients with SIHD undergoing PCI. Aspirin therapy is almost always continued indefinitely in patients with coronary artery disease. *High bleeding risk denotes those who have or develop a high risk of bleeding (eg, treatment with oral anticoagulant therapy) or are at increased risk of severe bleeding complication (eg, major intracranial surgery). SIHD, Stable ischemic heart disease; $H x$, history; $M I$, myocardial infarction; $P C I$, percutaneous coronary intervention; $C A B G$, coronary artery bypass graft surgery; $D A P T$, dual antiplatelet therapy; $S / P$, status post; $B M S$, bare metal stent; $D E S$, drug-eluting stent.

post-MI patients was in patients in whom $\mathrm{P}_{2} \mathrm{Y}_{12}$ inhibitor therapy either had not been discontinued or had been discontinued for $\leq 30$ days (absolute reduction in MACE: $1.9 \%$ to $2.5 \%$ ). No benefit was seen in patients in whom $\mathrm{P}_{2} \mathrm{Y}_{12}$ inhibitor therapy had been discontinued $>1$ year before enrollment in the study. ${ }^{42}$ Decisions about treatment with and duration of DAPT in patients with ACS require a thoughtful assessment of the benefit/risk ratio, integration of study data, and consideration of patient preference.

In patients treated with DAPT with high bleeding risk (eg, oral anticoagulation), increased risk of severe bleeding complications (eg, major intracranial surgery), or significant overt bleeding, the benefit/risk ratio may favor shorter-than-recommended duration of DAPT. ${ }^{17-21,34,36}$

Recommendations for DAPT in patients with ACS treated with medical therapy alone, fibrinolytic therapy, $\mathrm{PCI}$, and CABG are summarized in Figure 5.

\section{PERIOPERATIVE MANAGEMENT-TIMING OF ELECTIVE NONCARDIAC SURGERY IN PATIENTS TREATED WITH PCI AND DAPT: RECOMMENDATIONS}

See Online Data Supplement 12 for evidence supporting these recommendations.

Recommendations for Perioperative Management-Timing of Elective Noncardiac Surgery in Patients Treated With PCI and DAPT

\begin{tabular}{|c|l|l|}
\hline COR & LOE & Recommendations \\
\hline I & B-NR & $\begin{array}{l}\text { Elective noncardiac surgery should be delayed } 30 \text { days } \\
\text { after BMS implantation and optimally } 6 \text { months after } \\
\text { DES implantation. }{ }^{101-103,143-146}\end{array}$ \\
\hline I & $\begin{array}{l}\text { In patients treated with DAPT after coronary stent } \\
\text { implantation who must undergo surgical procedures that } \\
\text { mandate the discontinuation of } \mathrm{P}_{12} \text { inhibitor therapy, it } \\
\text { is recommended that aspirin be continued if possible and } \\
\text { the P2Y } \\
\text { as possible after surgery. }\end{array}$ \\
\hline
\end{tabular}


Recommendations for Perioperative Management-Timing of Elective Noncardiac Surgery in Patients Treated With PCI and DAPT (Continued)

\begin{tabular}{|c|c|c|}
\hline COR & LOE & Recommendations \\
\hline Ila & C-EO & $\begin{array}{l}\text { When noncardiac surgery is required in patients } \\
\text { currently taking a } \mathrm{P} 2 \mathrm{Y}_{12} \text { inhibitor, a consensus decision } \\
\text { among treating clinicians as to the relative risks } \\
\text { of surgery and discontinuation or continuation of } \\
\text { antiplatelet therapy can be useful. }\end{array}$ \\
\hline Ilb & C-EO & $\begin{array}{l}\text { Elective noncardiac surgery after DES implantation in } \\
\text { patients for whom } \mathrm{P} 2 \mathrm{Y}_{12} \text { inhibitor therapy will need to } \\
\text { be discontinued may be considered after } 3 \text { months if } \\
\text { the risk of further delay of surgery is greater than the } \\
\text { expected risks of stent thrombosis. }\end{array}$ \\
\hline l: Harm & B-NR & $\begin{array}{l}\text { Elective noncardiac surgery should not be performed } \\
\text { within } 30 \text { days after BMS implantation or within } 3 \\
\text { months after DES implantation in patients in whom DAPT } \\
\text { will need to be discontinued perioperatively. }{ }^{101-103,143-146}\end{array}$ \\
\hline
\end{tabular}

The timing of noncardiac surgery in patients treated with coronary stent implantation involves consideration of: (1) the risk of stent thrombosis (particularly if DAPT needs to be interrupted); (2) the consequences of delaying the desired surgical procedure; and (3) increased the intraand peri-procedural bleeding risk and the consequences of such bleeding if DAPT is continued ${ }^{15,147,148}$ (Data Supplement 12). DAPT significantly reduces the risk of stent thrombosis, ${ }^{50,51,94,95,99}$ and discontinuation of DAPT in the weeks after stent implantation is one of the strongest risk factors for stent thrombosis, with the magnitude of risk and impact on mortality rate inversely proportional to the timing of occurrence after the procedure. ${ }^{145,149,150}$ Older observational studies found that the risk of stent-related thrombotic complications is highest in the first 4 to 6 weeks after stent implantation but continues to be elevated at least 1 year after DES placement. ${ }^{101-103,149}$ Data from more recent large observational studies suggest that the time frame of increased risk of

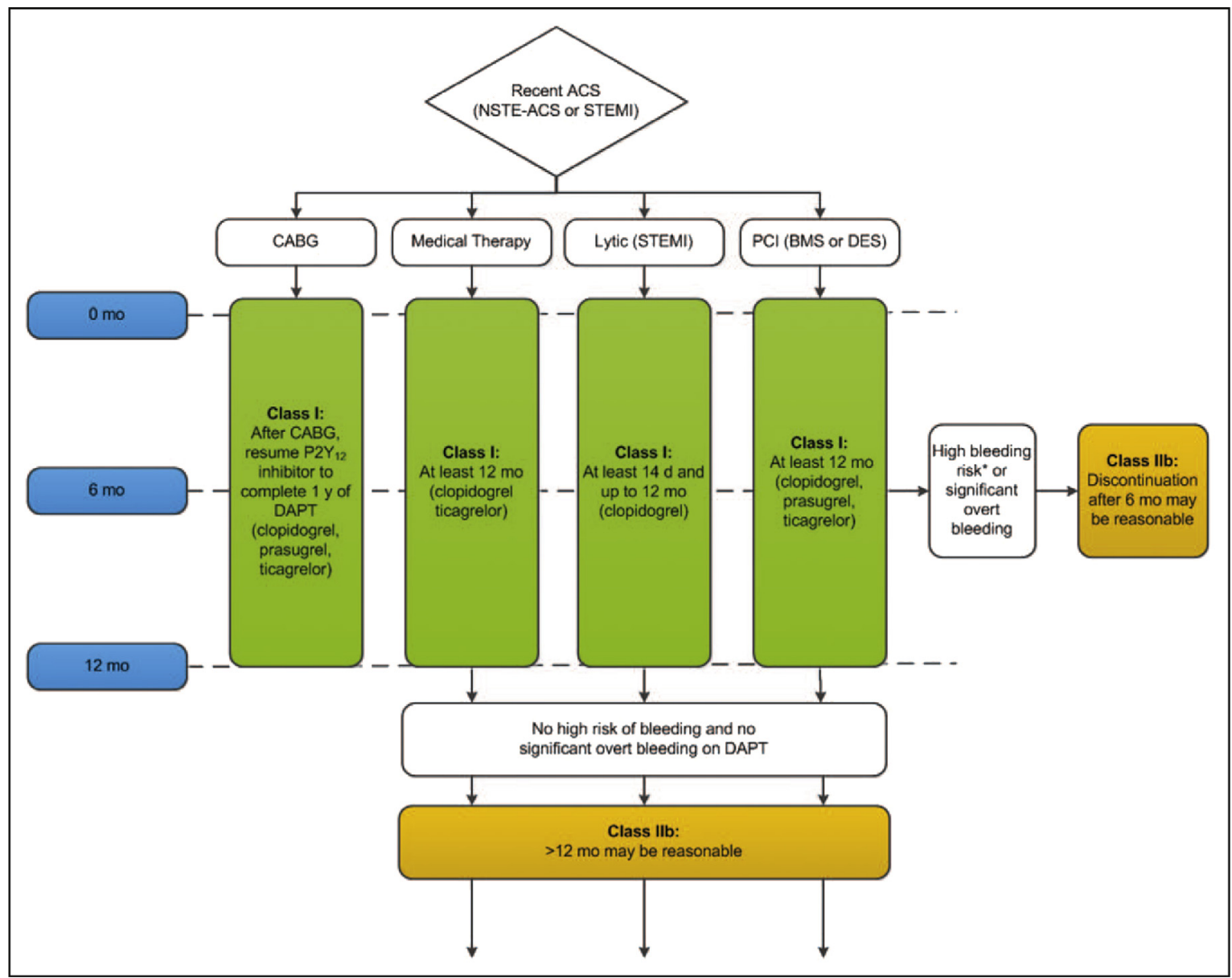

FIGURE 5. Treatment algorithm for duration of $\mathrm{P}_{2} \mathrm{Y}_{12}$ inhibitor therapy in patients with recent ACS (NSTE-ACS or STEMI). Colors correspond to Class of Recommendation in Table 1. Arrows at the bottom of the figure denote that the optimal duration of prolonged DAPT is not established. Aspirin therapy is almost always continued indefinitely in patients with coronary artery disease. *High bleeding risk denotes those who have or develop a high risk of bleeding (eg, treatment with oral anticoagulant therapy) or are at increased risk of severe bleeding complication (eg, major intracranial surgery). ACS, Acute coronary syndrome; NSTE-ACS, non-ST-elevation acute coronary syndrome; STEMI, ST-elevation myocardial infarction; $C A B G$, coronary artery bypass graft surgery; lytic, fibrinolytic therapy; $P C I$, percutaneous coronary intervention; $B M S$, bare metal stent; $D E S$, drug-eluting stent; $D A P T$, dual antiplatelet therapy. 


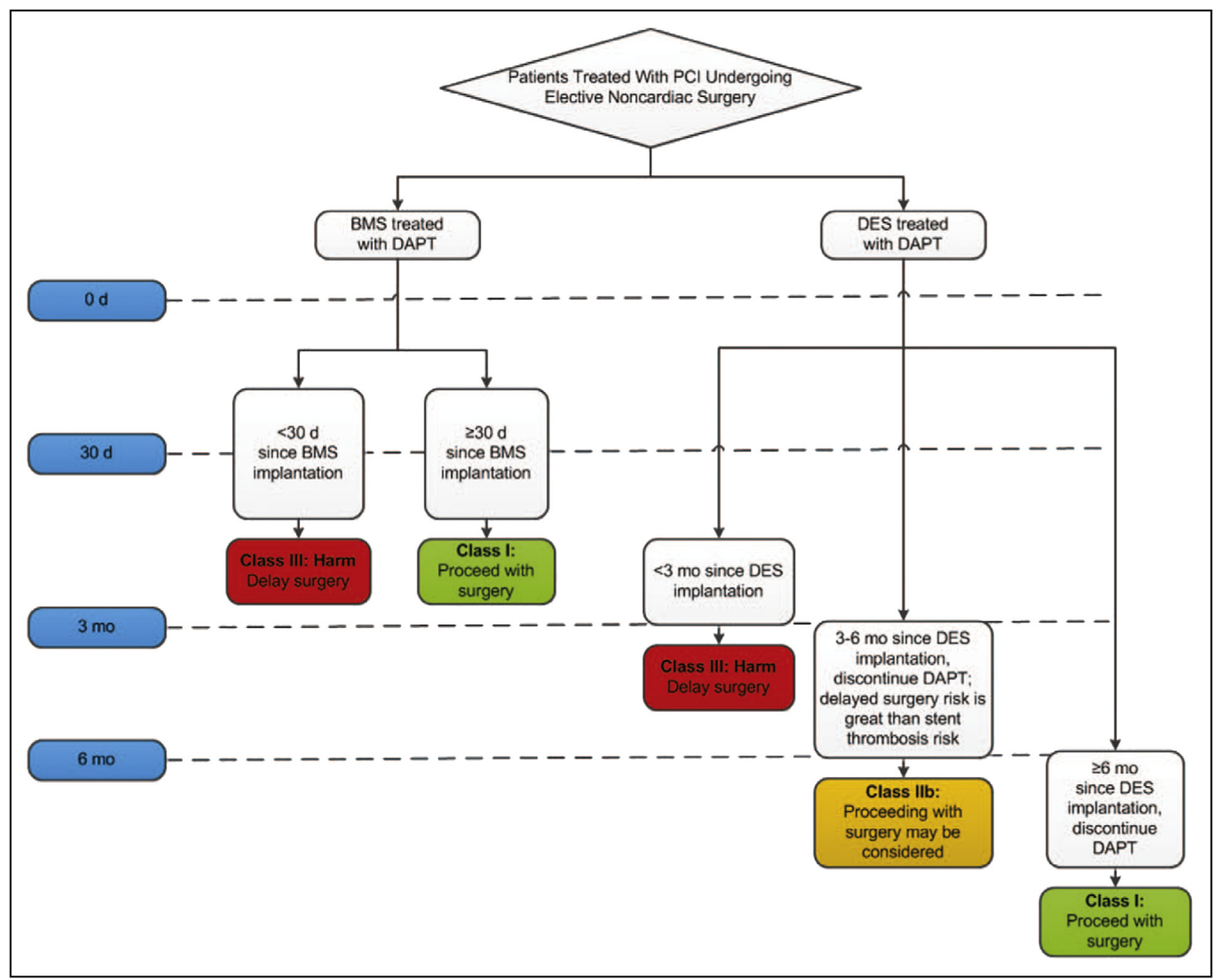

FIGURE 6. Treatment algorithm for the timing of elective noncardiac surgery in patients with coronary stents. Colors correspond to Class of Recommendation in Table 1. PCI, Percutaneous coronary intervention; BMS, bare metal stent; DAPT, dual antiplatelet therapy; DES, drug-eluting stent.

stent thrombosis is on the order of 6 months, irrespective of stent type (BMS or DES) ${ }^{151-153}$ In a large cohort of patients from the Veterans Health Administration hospitals, the increased risk of surgery for the 6 months after stent placement was most pronounced in those patients in whom the indication for PCI was an MI. ${ }^{146}$ An additional consideration, irrespective of the timing of surgery, is that surgery is associated with proinflammatory and prothrombotic effects that may increase the risk of coronary thrombosis at the level of the stented vascular segment as well as throughout the coronary vasculature. ${ }^{154,155}$

Prior recommendations with regard to duration of DAPT $^{9,104}$ and the timing of noncardiac surgery ${ }^{15,156}$ in patients treated with DES were based on observations of those treated with first-generation DES. Compared with first-generation DES, currently used newer-generation DES are associated with a lower risk of stent thrombosis and appear to require a shorter minimum duration of
DAPT $^{17,18,21,38,96,97}$ Several studies of DAPT duration in patients treated with newer-generation DES did not detect any difference in the risk of stent thrombosis between patients treated with 3 to 6 months of DAPT or patients treated with longer durations of DAPT (although these studies were underpowered to detect such differences) ${ }^{17-21}$ (Data Supplement 1). Moreover, the safety of treating selected patients with newer-generation DES for shorter durations ( 3 or 6 months) of DAPT has been shown in a patient-level analysis pooling 4 trials evaluating DAPT durations. ${ }^{34}$ Furthermore, in the PARIS (Patterns of Nonadherence to Antiplatelet Regimens in Stented Patients) registry, interruption of DAPT according to physician judgment in patients undergoing surgery at any time point after PCI was not associated with an increased risk of MACE. ${ }^{145}$ On the basis of these considerations, the prior Class I recommendation that elective noncardiac surgery in patients treated with DES be 
delayed 1 year ${ }^{15}$ has been modified to "optimally at least 6 months." Similarly, the prior Class IIb recommendation that elective noncardiac surgery in patients treated with DES may be considered after 180 days ${ }^{15}$ has been modified to "after 3 months." Figure 6 summarizes recommendations on timing of elective noncardiac surgery in patients with coronary stents.

The magnitude of incremental bleeding risk in patients treated with antiplatelet therapy who undergo surgery is uncertain. ${ }^{157,158}$ If $\mathrm{P}_{2} \mathrm{Y}_{12}$ inhibitor therapy needs to be held in patients being treated with DAPT after stent implantation, continuation of aspirin therapy if possible is recommended, though this is based primarily on expert opinion. If a $\mathrm{P}_{2} \mathrm{Y}_{12}$ inhibitor has been held before a surgical procedure, therapy is restarted as soon as possible, given the substantial thrombotic hazard associated with lack of platelet inhibition early after surgery in patients with recent stent implantation. Although several small studies have used intravenous antiplatelet agents as a means of "bridging" in patients requiring temporary discontinuation of DAPT before surgery, there is no convincing clinical evidence demonstrating the efficacy of bridging with either parenteral antiplatelet or anticoagulant therapy. ${ }^{159-163}$

Decisions about the timing of surgery and whether to discontinue DAPT after coronary stent implantation are best individualized. Such decisions involve weighing the particular surgical procedure and the risks of delaying the procedure, the risks of ischemia and stent thrombosis, and the risk and consequences of bleeding. Given the complexity of these considerations, decisions are best determined by a consensus of the surgeon, anesthesiologist, cardiologist, and patient.

\section{PRESIDENTS AND STAFF}

\section{American College of Cardiology}

Kim A. Williams, Sr, MD, FACC, FAHA, President

Shalom Jacobovitz, Chief Executive Officer

William J. Oetgen, MD, MBA, FACC, Executive Vice

President, Science, Education, Quality, and Publishing

Amelia Scholtz, PhD, Publications Manager, Science,

Education, Quality, and Publishing

\section{American College of Cardiology/American Heart Association \\ Melanie Stephens-Lyman, MSc, Director, Guideline Operations and Strategy \\ Lisa Bradfield, CAE, Director, Guideline Methodology and Policy \\ Abdul R. Abdullah, MD, Associate Science and Medicine Advisor \\ Clara Fitzgerald, Project Manager, Science and Clinical Policy}

\section{American Heart Association}

Mark A. Creager, MD, FAHA, FACC, President

Nancy Brown, Chief Executive Officer

Rose Marie Robertson, MD, FAHA, Chief Science and

Medical Officer

Gayle R. Whitman, PhD, RN, FAHA, FAAN, Senior Vice

President, Office of Science Operations

Comilla Sasson, MD, PhD, FACEP, Vice President for

Science and Medicine

Jody Hundley, Production Manager, Scientific Publications,

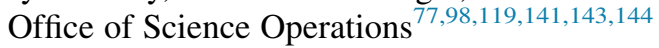

\section{References}

1. ACCF/AHA Task Force on Practice Guidelines. Methodology Manual and Policies From the ACCF/AHA Task Force on Practice Guidelines. Available at: http://assets.cardiosource.com/Methodology_Manual_for_ACC_ AHA_Writing_Committees.pdf and http://my.americanheart.org/idc/groups/ ahamah-public/@wcm/@sop/documents/downloadable/ucm_319826.pdf. American College of Cardiology and American Heart Association. Accessed January 23, 2015.

2. Committee on Standards for Developing Trustworthy Clinical Practice Guidelines, Institute of Medicine (US). Clinical Practice Guidelines We Can Trust. Washington, DC: National Academies Press; 2011.

3. Committee on Standards for Systematic Reviews of Comparative Effectiveness Research, Institute of Medicine (US). Finding What Works in Health Care: Standards for Systematic Reviews. Washington, DC: National Academies Press; 2011.

4. Anderson JL, Heidenreich PA, Barnett PG, et al. ACC/AHA statement on cost/ value methodology in clinical practice guidelines and performance measures: a report of the American College of Cardiology/American Heart Association Task Force on Performance Measures and Task Force on Practice Guidelines. Circulation. 2014;129:2329-45.

5. Arnett DK, Goodman RA, Halperin JL, et al. AHA/ACC/HHS strategies to enhance application of clinical practice guidelines in patients with cardiovascular disease and comorbid conditions: from the American Heart Association, American College of Cardiology, and U.S. Department of Health and Human Services. Circulation. 2014;130:1662-7.

6. Jacobs AK, Kushner FG, Ettinger SM, et al. ACCF/AHA clinical practice guideline methodology summit report: a report of the American College of Cardiology Foundation/American Heart Association Task Force on Practice Guidelines. Circulation. 2013;127:268-310.

7. Jacobs AK, Anderson JL, Halperin JL. The evolution and future of ACC/AHA clinical practice guidelines: a 30-year journey: a report of the American College of Cardiology/American Heart Association Task Force on Practice Guidelines. Circulation. 2014;130:1208-17.

8. Halperin JL, Levine GN, Al-Khatib SM, et al. Further Evolution of the ACC/AHA Clinical Practice Guideline Recommendation Classification Sys tem: a report of the American College of Cardiology/American Heart Association Task Force on Clinical Practice Guidelines. Circulation. 2016; 133:1426-8.

9. Levine GN, Bates ER, Blankenship JC, et al. 2011 ACCF/AHA/SCAI guideline for percutaneous coronary intervention: a report of the American College of Cardiology Foundation/American Heart Association Task Force on Practice Guidelines and the Society for Cardiovascular Angiography and Interventions. Circulation. 2011;124:e574-651.

10. Hillis LD, Smith PK, Anderson JL, et al; 2011 ACCF/AHA guideline for coronary artery bypass graft surgery: a report of the American College of Cardiology Foundation/American Heart Association Task Force on Practice Guidelines. Developed in collaboration with the American Association for Thoracic Surgery, Society of Cardiovascular Anesthesiologists, and Society of Thoracic Surgeons. Circulation. 2011;124: e652-735.

11. Fihn SD, Blankenship JC, Alexander KP, et al. 2014 ACC/AHA/AATS/PCNA/ SCAI/STS focused update of the guideline for the diagnosis and management of patients with stable ischemic heart disease: a report of the American College of Cardiology/American Heart Association Task Force on Practice Guidelines, and the American Association for Thoracic Surgery, Preventive Cardiovascular 
Nurses Association, Society for Cardiovascular Angiography and Interventions, and Society of Thoracic Surgeons. Circulation. 2014;130:1749-67.

12. Fihn SD, Gardin JM, Abrams J, et al. 2012 ACCF/AHA/ACP/AATS/PCNA/ SCAI/STS guideline for the diagnosis and management of patients with stable ischemic heart disease: a report of the American College of Cardiology Foundation/American Heart Association Task Force on Practice Guidelines, and the American College of Physicians, American Association for Thoracic Surgery, Preventive Cardiovascular Nurses Association, Society for Cardiovascular Angiography and Interventions, and Society of Thoracic Surgeons. Circulation. 2012;126:3097-137.

13. O'Gara PT, Kushner FG, Ascheim DD, et al. 2013 ACCF/AHA guideline for the management of ST-elevation myocardial infarction: a report of the American College of Cardiology Foundation/American Heart Association Task Force on Practice Guidelines. Circulation. 2013;127:e362-425.

14. Amsterdam EA, Wenger NK, Brindis RG, et al. 2014 AHA/ACC guideline for the management of patients with non-ST-elevation acute coronary syndromes: a report of the American College of Cardiology/American Heart Association Task Force on Practice Guidelines. Circulation. 2014;130: e344-426.

15. Fleisher LA, Fleischmann KE, Auerbach AD, et al. 2014 ACC/AHA guideline on perioperative cardiovascular evaluation and management of patients undergoing noncardiac surgery: a report of the American College of Cardiology/ American Heart Association Task Force on Practice Guidelines. Circulation. 2014;130:e278-333.

16. Mauri L, Kereiakes DJ, Yeh RW, et al. Twelve or 30 months of dual antiplatelet therapy after drug-eluting stents. N Engl J Med. 2014;371:2155-66.

17. Colombo A, Chieffo A, Frasheri A, et al. Second-generation drug-eluting stent implantation followed by 6- versus 12-month dual antiplatelet therapy: the SECURITY randomized clinical trial. J Am Coll Cardiol. 2014;64: 2086-97.

18. Gwon H-C, Hahn J-Y, Park KW, et al. Six-month versus 12-month dual antiplatelet therapy after implantation of drug-eluting stents: the Efficacy of Xience/Promus Versus Cypher to Reduce Late Loss After Stenting (EXCELLENT) randomized, multicenter study. Circulation. 2012;125: 505-13.

19. Kim B-K, Hong M-K, Shin D-H, et al. A new strategy for discontinuation of dual antiplatelet therapy: the RESET Trial (REal Safety and Efficacy of 3 month dual antiplatelet Therapy following Endeavor zotarolimus-eluting stent implantation). J Am Coll Cardiol. 2012;60:1340-8.

20. Feres F, Costa RA, Abizaid A, et al. Three vs twelve months of dual antiplatelet therapy after zotarolimus-eluting stents: the OPTIMIZE randomized trial. JAMA. 2013;310:2510-22.

21. Schulz-Schüpke S, Byrne RA, Ten Berg JM, et al. ISAR-SAFE: a randomized, double-blind, placebo-controlled trial of 6 vs. 12 months of clopidogrel therapy after drug-eluting stenting. Eur Heart J. 2015;36:1252-63.

22. Park S-J, Park D-W, Kim Y-H, et al. Duration of dual antiplatelet therapy after implantation of drug-eluting stents. N Engl J Med. 2010;362:1374-82.

23. Valgimigli M, Campo G, Monti M, et al. Short- versus long-term duration of dual-antiplatelet therapy after coronary stenting: a randomized multicenter trial. Circulation. 2012;125:2015-26.

24. Collet J-P, Silvain J, Barthélémy O, et al. Dual-antiplatelet treatment beyond 1 year after drug-eluting stent implantation (ARCTIC-Interruption): a randomised trial. Lancet. 2014:384:1577-85.

25. Gilard M, Barragan P, Noryani AAL, et al. 6- versus 24-month dual antiplatelet therapy after implantation of drug-eluting stents in patients nonresistant to aspirin: the randomized, multicenter ITALIC trial. J Am Coll Cardiol. 2015; 65:777-86.

26. Lee CW, Ahn J-M, Park D-W, et al. Optimal duration of dual antiplatelet therapy after drug-eluting stent implantation: a randomized, controlled trial. Circulation. 2014;129:304-12.

27. Helft G, Steg PG, Le Feuvre C, et al. Stopping or continuing clopidogrel 12 months after drug-eluting stent placement: the OPTIDUAL randomized trial. Eur Heart J. 2016;37:365-74.

28. Bonaca MP, Bhatt DL, Cohen M, et al. Long-term use of ticagrelor in patients with prior myocardial infarction. N Engl J Med. 2015;372: 1791-800.

29. Roffi M, Patrono C, Collet J-P, et al. 2015 ESC guidelines for the management of acute coronary syndromes in patients presenting without persistent STsegment elevation: Task Force for the Management of Acute Coronary Syndromes in Patients Presenting without Persistent ST-Segment Elevation of the European Society of Cardiology (ESC). Eur Heart J. 2016;37:267-315.
30. Bittl JA, Baber U, Bradley SM, et al. Duration of dual antiplatelet therapy: a systematic review for the 2016 ACC/AHA guideline focused update on duration of dual antiplatelet therapy in patients with coronary artery disease: a report of the American College of Cardiology/American Heart Association Task Force on Clinical Practice Guidelines. Circulation. 2016;134:e123-55.

31. Steg PG, James SK, Atar D, et al. ESC guidelines for the management of acute myocardial infarction in patients presenting with ST-segment elevation. Eur Heart J. 2012;33:2569-619.

32. Wijns W, Kolh P, Danchin N, et al. Guidelines on myocardial revascularization. Eur Heart J. 2010;31:2501-55.

33. Hamm CW, Bassand J-P, Agewall S, et al. ESC guidelines for the management of acute coronary syndromes in patients presenting without persistent STsegment elevation: the Task Force for the Management of Acute Coronary Syndromes (ACS) in Patients Presenting Without Persistent ST-Segment Elevation of the European Society of Cardiology (ESC). Eur Heart J. 2011; 32:2999-3054.

34. Palmerini T, Sangiorgi D, Valgimigli M, et al. Short- versus long-term dual antiplatelet therapy after drug-eluting stent implantation: an individual patient data pairwise and network meta-analysis. J Am Coll Cardiol. 2015;65: 1092-102.

35. Palmerini T, Benedetto U, Bacchi-Reggiani L, et al. Mortality in patients treated with extended duration dual antiplatelet therapy after drug-eluting stent implantation: a pairwise and Bayesian network meta-analysis of randomised trials. Lancet. 2015;385:2371-82.

36. Giustino G, Baber U, Sartori S, et al. Duration of dual antiplatelet therapy after drug-eluting stent implantation: a systematic review and metaanalysis of randomized controlled trials. J Am Coll Cardiol. 2015;65: 1298-310.

37. Navarese EP, Andreotti F, Schulze V, et al. Optimal duration of dual antiplatelet therapy after percutaneous coronary intervention with drug eluting stents: metaanalysis of randomised controlled trials. BMJ. 2015;350:h1618.

38. Navarese EP, Tandjung K, Claessen B, et al. Safety and efficacy outcomes of first and second generation durable polymer drug eluting stents and biodegradable polymer biolimus eluting stents in clinical practice: comprehensive network meta-analysis. BMJ. 2013;347:f6530.

39. Hermiller JB, Krucoff MW, Kereiakes DJ, et al. Benefits and risks of extended dual antiplatelet therapy after everolimus-eluting stents. JACC Cardiovasc Interv. 2016;9:138-47.

40. Bhatt DL, Fox KAA, Hacke W, et al. Clopidogrel and aspirin versus aspirin alone for the prevention of atherothrombotic events. $N$ Engl J Med. 2006; 354:1706-17.

41. Bhatt DL, Flather MD, Hacke W, et al. Patients with prior myocardial infarction, stroke, or symptomatic peripheral arterial disease in the CHARISMA trial. J Am Coll Cardiol. 2007;49:1982-8.

42. Bonaca MP, Bhatt DL, Steg PG, et al. Ischaemic risk and efficacy of ticagrelor in relation to time from $\mathrm{P}_{2} \mathrm{Y}_{12}$ inhibitor withdrawal in patients with prior myocardial infarction: insights from PEGASUS-TIMI 54. Eur Heart J. 2015 [Epub ahead of print].

43. Yeh RW, Kereiakes DJ, Steg PG, et al. Benefits and risks of extended duration dual antiplatelet therapy after PCI in patients with and without acute myocardial infarction. J Am Coll Cardiol. 2015;65:2211-21.

44. Udell JA, Bonaca MP, Collet J-P, et al. Long-term dual antiplatelet therapy for secondary prevention of cardiovascular events in the subgroup of patients with previous myocardial infarction: a collaborative meta-analysis of randomized trials. Eur Heart J. 2016:37:390-9.

45. Mauri L, Elmariah S, Yeh RW, et al. Causes of late mortality with dual antiplatelet therapy after coronary stents. Eur Heart J. 2016;37:378-85.

46. Spencer FA, Prasad M, Vandvik PO, et al. Longer versus shorter-duration dualantiplatelet therapy after drug-eluting stent placement: a systematic review and meta-analysis. Ann Intern Med. 2015;163:118-26.

47. Montalescot G, Brieger D, Dalby AJ, et al. Duration of dual antiplatelet therapy after coronary stenting: a review of the evidence. J Am Coll Cardiol. 2015;66: 832-47.

48. Elmariah S, Mauri L, Doros G, et al. Extended duration dual antiplatelet therapy and mortality: a systematic review and meta-analysis. Lancet. 2015;385:792-8.

49. US Food and Drug Administration. FDA Drug Safety Communication: FDA review finds long-term treatment with blood-thinning medicine Plavix (clopidogrel) does not change risk of death. Available at: http:/www.fda.gov/Drugs/ DrugSafety/ucm471286.htm. Published November 6, 2015; updated December 9, 2015. Accessed February 17, 2016. 
50. Steinhubl SR, Berger PB, Mann JT 3rd, et al. Early and sustained dual oral antiplatelet therapy following percutaneous coronary intervention: a randomized controlled trial. JAMA. 2002;288:2411-20.

51. Mehta SR, Yusuf S, Peters RJ, et al. Effects of pretreatment with clopidogrel and aspirin followed by long-term therapy in patients undergoing percutaneous coronary intervention: the PCI-CURE study. Lancet. 2001;358:527-33.

52. Yusuf S, Zhao F, Mehta SR, et al. Effects of clopidogrel in addition to aspirin in patients with acute coronary syndromes without ST-segment elevation. $N$ Engl J Med. 2001;345:494-502.

53. Wallentin L, Becker RC, Budaj A, et al. Ticagrelor versus clopidogrel in patients with acute coronary syndromes. $N$ Engl J Med. 2009;361:1045-57.

54. Wiviott SD, Braunwald E, McCabe CH, et al. Prasugrel versus clopidogrel in patients with acute coronary syndromes. N Engl J Med. 2007;357:2001-15.

55. Montalescot G, Wiviott SD, Braunwald E, et al. Prasugrel compared with clopidogrel in patients undergoing percutaneous coronary intervention for STelevation myocardial infarction (TRITON-TIMI 38): double-blind, randomised controlled trial. Lancet. 2009;373:723-31.

56. Antithrombotic Trialists' Collaboration. Collaborative meta-analysis of randomised trials of antiplatelet therapy for prevention of death, myocardial infarction, and stroke in high risk patients. BMJ. 2002;324:71-86.

57. Patrono C, Baigent C, Hirsh J, et al. Antiplatelet drugs: American College of Chest Physicians Evidence-Based Clinical Practice Guidelines (8th Edition). Chest. 2008;133:199S-233S.

58. Peters RJG, Mehta SR, Fox KAA, et al. Effects of aspirin dose when used alone or in combination with clopidogrel in patients with acute coronary syndromes: observations from the Clopidogrel in Unstable angina to prevent Recurrent Events (CURE) study. Circulation. 2003;108:1682-7.

59. Steinhubl SR, Bhatt DL, Brennan DM, et al. Aspirin to prevent cardiovascular disease: the association of aspirin dose and clopidogrel with thrombosis and bleeding. Ann Intern Med. 2009;150:379-86,

60. Mehta SR, Tanguay J-F, Eikelboom JW, et al. Double-dose versus standarddose clopidogrel and high-dose versus low-dose aspirin in individuals undergoing percutaneous coronary intervention for acute coronary syndromes (CURRENT-OASIS 7): a randomised factorial trial. Lancet. 2010;376:1233-43.

61. Yeh RW, Secemsky E, Kereiakes DJ, et al. Development and validation of a prediction rule for benefit and harm of dual antiplatelet therapy beyond one year after percutaneous coronary intervention: an analysis from the randomized Dual Antiplatelet Therapy Study. JAMA. 2016;315:1735-49.

62. Califf RM, Armstrong PW, Carver JR, et al. 27th Bethesda Conference: matching the intensity of risk factor management with the hazard for coronary disease events. Task Force 5. Stratification of patients into high, medium and low risk subgroups for purposes of risk factor management. J Am Coll Cardiol. 1996;27: $1007-19$.

63. Sachdev M, Sun JL, Tsiatis AA, et al. The prognostic importance of comorbidity for mortality in patients with stable coronary artery disease. J Am Coll Cardiol. 2004;43:576-82.

64. Binder RK, Lüscher TF, O'Connor SA. Duration of dual antiplatelet therapy after coronary artery stenting: where is the sweet spot between ischaemia and bleeding? Eur Heart J. 2015;36:1207-11.

65. Subherwal S, Bach RG, Chen AY, et al. Baseline risk of major bleeding in nonST-segment-elevation myocardial infarction: the CRUSADE (Can Rapid risk stratification of Unstable angina patients Suppress ADverse outcomes with Early implementation of the ACC/AHA Guidelines) Bleeding Score. Circulation. 2009; 119:1873-82.

66. Moscucci M, Fox KA, Cannon CP, et al. Predictors of major bleeding in acute coronary syndromes: the Global Registry of Acute Coronary Events (GRACE). Eur Heart J. 2003;24:1815-23

67. Mehran R, Pocock SJ, Nikolsky E, et al. A risk score to predict bleeding in patients with acute coronary syndromes. J Am Coll Cardiol. 2010;55:2556-66.

68. Baber U, Mehran R, Sharma SK, et al. Impact of the everolimus-eluting stent on stent thrombosis: a meta-analysis of 13 randomized trials. J Am Coll Cardiol. 2011;58:1569-77.

69. Cayla G, Hulot J-S, O'Connor SA, et al. Clinical, angiographic, and genetic factors associated with early coronary stent thrombosis. JAMA. 2011;306:1765-74.

70. Campo G, Tebaldi M, Vranckx P, et al. Short- versus long-term duration of dual antiplatelet therapy in patients treated for in-stent restenosis: a PRODIGY trial substudy (Prolonging Dual Antiplatelet Treatment After Grading Stent-Induced Intimal Hyperplasia). J Am Coll Cardiol. 2014;63:506-12.

71. James SK, Roe MT, Cannon CP, et al. Ticagrelor versus clopidogrel in patients with acute coronary syndromes intended for non-invasive management: sub- study from prospective randomised PLATelet inhibition and patient Outcomes (PLATO) trial. BMJ. 2011;342:d3527.

72. Steg PG, James S, Harrington RA, et al. Ticagrelor versus clopidogrel in patients with ST-elevation acute coronary syndromes intended for reperfusion with primary percutaneous coronary intervention: a Platelet Inhibition and $\mathrm{Pa}$ tient Outcomes (PLATO) trial subgroup analysis. Circulation. 2010;122: 2131-41.

73. US Food and Drug Administration. Medical Device Reporting (MDR). Available at: http://www.fda.gov/MedicalDevices/Safety/ReportaProblem/default. htm. Updated July 16, 2015; accessed February 17, 2016.

74. Abraham NS, Hlatky MA, Antman EM, et al. ACCF/ACG/AHA 2010 exper consensus document on the concomitant use of proton pump inhibitors and thienopyridines: a focused update of the ACCF/ACG/AHA 2008 expert consensus document on reducing the gastrointestinal risks of antiplatelet therapy and NSAID use: a report of the American College of Cardiology Foundation Task Force on Expert Consensus Documents. Circulation. 2010;122:2619-33.

75. Serebruany VL, Steinhubl SR, Berger PB, et al. Analysis of risk of bleeding complications after different doses of aspirin in 192,036 patients enrolled in 31 randomized controlled trials. Am J Cardiol. 2005;95:1218-22.

76. Jolly SS, Pogue J, Haladyn K, et al. Effects of aspirin dose on ischaemic events and bleeding after percutaneous coronary intervention: insights from the PCICURE study. Eur Heart J. 2009;30:900-7.

77. Lorenz RL, Schacky CV, Weber M, et al. Improved aortocoronary bypass patency by low-dose aspirin (100 mg daily): effects on platelet aggregation and thromboxane formation. Lancet. 1984;1:1261-4.

78. Xian Y, Wang TY, McCoy LA, et al. Association of discharge aspirin dose with outcomes after acute myocardial infarction: insights from the Treatment with ADP Receptor Inhibitors: Longitudinal Assessment of Treatment Patterns and Events After Acute Coronary Syndrome (TRANSLATE-ACS) Study. Circulation. 2015;132:174-81.

79. Montalescot G, Drobinski G, Maclouf J, et al. Evaluation of thromboxane production and complement activation during myocardial ischemia in patients with angina pectoris. Circulation. 1991;84:2054-62.

80. Patrono C, Ciabattoni G, Patrignani P, et al. Clinical pharmacology of platelet cyclooxygenase inhibition. Circulation. 1985;72:1177-84.

81. Steinhubl SR, Berger PB. Aspirin following PCI: too much of a good thing? Eur Heart J. 2009;30:882-4

82. Mahaffey KW, Wojdyla DM, Carroll K, et al. Ticagrelor compared with clopidogrel by geographic region in the Platelet Inhibition and Patient Outcomes (PLATO) trial. Circulation. 2011;124:544-54.

83. National Patient-Centered Clinical Research Network. ADAPTABLE, the Aspirin Study - A Patient-Centered Trial. Available at: http://theaspirinstudy. org. Accessed February 17, 2016.

84. Dans AL, Connolly SJ, Wallentin L, et al. Concomitant use of antiplatelet therapy with dabigatran or warfarin in the Randomized Evaluation of Long-Term Anticoagulation Therapy (RE-LY) trial. Circulation. 2013;127:634-40.

85. Faxon DP, Eikelboom JW, Berger PB, et al. Consensus document: antithrombotic therapy in patients with atrial fibrillation undergoing coronary stenting: a North-American perspective. Thromb Haemost. 2011;106:572-84.

86. Hansen ML, Srensen R, Clausen MT, et al. Risk of bleeding with single, dual, or triple therapy with warfarin, aspirin, and clopidogrel in patients with atrial fibrillation. Arch Intern Med. 2010;170:1433-41.

87. Sørensen R, Hansen ML, Abildstrom SZ, et al. Risk of bleeding in patients with acute myocardial infarction treated with different combinations of aspirin, clopidogrel, and vitamin $\mathrm{K}$ antagonists in Denmark: a retrospective analysis of nationwide registry data. Lancet. 2009;374:1967-74.

88. Lip GYH, Windecker S, Huber K, et al. Management of antithrombotic therapy in atrial fibrillation patients presenting with acute coronary syndrome and/or undergoing percutaneous coronary or valve interventions: a joint consensus document of the European Society of Cardiology Working Group on Thrombosis, European Heart Rhythm Association (EHRA), European Association of Percutaneous Cardiovascular Interventions (EAPCI) and European Association of Acute Cardiac Care (ACCA). Eur Heart J. 2014;35:3155-79.

89. Dewilde WJM, Oirbans T, Verheugt FWA, et al. Use of clopidogrel with or without aspirin in patients taking oral anticoagulant therapy and undergoing percutaneous coronary intervention: an open-label, randomised, controlled trial. Lancet. 2013;381:1107-15.

90. Fiedler KA, Maeng M, Mehilli J, et al. Duration of triple therapy in patients requiring oral anticoagulation after drug-eluting stent implantation: the ISAR-TRIPLE Trial. J Am Coll Cardiol. 2015;65:1619-29. 
91. Dewilde WJM, Janssen PWA, Verheugt FWA, et al. Triple therapy for atrial fibrillation and percutaneous coronary intervention: a contemporary review. $J$ Am Coll Cardiol. 2014;64:1270-80.

92. Moser M, Olivier CB, Bode C. Triple antithrombotic therapy in cardiac patients: more questions than answers. Eur Heart J. 2014;35:216-23.

93. Capodanno D, Angiolillo DJ. Management of antiplatelet and anticoagulant therapy in patients with atrial fibrillation in the setting of acute coronary syndromes or percutaneous coronary interventions. Circ Cardiovasc Interv. 2014; $7: 113-24$

94. Leon MB, Baim DS, Popma JJ, et al. A clinical trial comparing three antithrombotic-drug regimens after coronary-artery stenting. Stent Anticoagulation Restenosis Study Investigators. N Engl J Med. 1998;339:1665-71.

95. Schömig A, Neumann FJ, Kastrati A, et al. A randomized comparison of antiplatelet and anticoagulant therapy after the placement of coronary-artery stents. N Engl J Med. 1996;334:1084-9.

96. Brar SS, Kim J, Brar SK, et al. Long-term outcomes by clopidogrel duration and stent type in a diabetic population with de novo coronary artery lesions. J Am Coll Cardiol. 2008;51:2220-7.

97. Eisenstein EL, Anstrom KJ, Kong DF, et al. Clopidogrel use and long-term clinical outcomes after drug-eluting stent implantation. JAMA. 2007;297: 159-68.

98. Sabatine MS, Cannon CP, Gibson CM, et al. Effect of clopidogrel pretreatment before percutaneous coronary intervention in patients with ST-elevation myocardial infarction treated with fibrinolytics: the PCI-CLARITY study. JAMA. 2005;294:1224-32.

99. Cutlip DE, Baim DS, Ho KK, et al. Stent thrombosis in the modern era: a pooled analysis of multicenter coronary stent clinical trials. Circulation. 2001;103: 1967-71.

100. Wilson SH, Rihal CS, Bell MR, et al. Timing of coronary stent thrombosis in patients treated with ticlopidine and aspirin. Am J Cardiol. 1999;83:1006-11.

101. Kaluza GL, Joseph J, Lee JR, et al. Catastrophic outcomes of noncardiac surgery soon after coronary stenting. J Am Coll Cardiol. 2000;35:1288-94.

102. Wilson SH, Fasseas P, Orford JL, et al. Clinical outcome of patients undergoing non-cardiac surgery in the two months following coronary stenting. J Am Coll Cardiol. 2003;42:234-40.

103. Nuttall GA, Brown MJ, Stombaugh JW, et al. Time and cardiac risk of surgery after bare-metal stent percutaneous coronary intervention. Anesthesiology. 2008;109:588-95.

104. Grines CL, Bonow RO, Casey DE, et al. Prevention of premature discontinuation of dual antiplatelet therapy in patients with coronary artery stents: a science advisory from the American Heart Association, American College of Cardiology, Society for Cardiovascular Angiography and Interventions, American College of Surgeons, and American Dental Association, with representation from the American College of Physicians. Circulation. 2007; 115:813-8.

105. Pfisterer M, Brunner-La Rocca HP, Buser PT, et al. Late clinical events after clopidogrel discontinuation may limit the benefit of drug-eluting stents: an observational study of drug-eluting versus bare-metal stents. J Am Coll Cardiol. 2006;48:2584-91.

106. Navarese EP, Kowalewski M, Kandzari D, et al. First-generation versus secondgeneration drug-eluting stents in current clinical practice: updated evidence from a comprehensive meta-analysis of randomised clinical trials comprising 31379 patients. Open Heart. 2014;1:e000064.

107. Palmerini T, Kirtane AJ, Serruys PW, et al. Stent thrombosis with everolimuseluting stents: meta-analysis of comparative randomized controlled trials. Circ Cardiovasc Interv. 2012;5:357-64.

108. Räber L, Magro M, Stefanini GG, et al. Very late coronary stent thrombosis of a newer-generation everolimus-eluting stent compared with early-generation drug-eluting stents: a prospective cohort study. Circulation. 2012;125:1110-21.

109. Sarno G, Lagerqvist B, Nilsson J, et al. Stent thrombosis in new-generation drug-eluting stents in patients with STEMI undergoing primary PCI: a report from SCAAR. J Am Coll Cardiol. 2014;64:16-24.

110. Kočka V, Malý M, Toušek P, et al. Bioresorbable vascular scaffolds in acute STsegment elevation myocardial infarction: a prospective multicentre study "Prague 19" Eur Heart J. 2014;35:787-94.

111. Kereiakes DJ, Meredith IT, Windecker S, et al. Efficacy and safety of a novel bioabsorbable polymer-coated, everolimus-eluting coronary stent: the EVOLVE II Randomized Trial. Circ Cardiovasc Interv. 2015;8:e02372.

112. Puricel S, Arroyo D, Corpataux N, et al. Comparison of everolimus- and biolimus-eluting coronary stents with everolimus-eluting bioresorbable vascular scaffolds. J Am Coll Cardiol. 2015;65:791-801.
113. Gao R, Yang Y, Han Y, et al. Bioresorbable vascular scaffolds versus metallic stents in patients with coronary artery disease: ABSORB China Trial. J Am Coll Cardiol. 2015;66:2298-309.

114. Windecker S, Serruys PW, Wandel S, et al. Biolimus-eluting stent with biodegradable polymer versus sirolimus-eluting stent with durable polymer for coronary revascularisation (LEADERS): a randomised non-inferiority trial. Lancet. 2008;372:1163-73.

115. Meredith IT, Verheye S, Dubois CL, et al. Primary endpoint results of the EVOLVE trial: a randomized evaluation of a novel bioabsorbable polymercoated, everolimus-eluting coronary stent. J Am Coll Cardiol. 2012;59:1362-70.

116. Ellis SG, Kereiakes DJ, Metzger DC, et al. Everolimus-eluting bioresorbable scaffolds for coronary artery disease. N Engl J Med. 2015;373:1905-15.

117. Urban P, Meredith IT, Abizaid A, et al. Polymer-free drug-coated coronary stents in patients at high bleeding risk. N Engl J Med. 2015;373:2038-47.

118. Fox KAA, Mehta SR, Peters R, et al. Benefits and risks of the combination of clopidogrel and aspirin in patients undergoing surgical revascularization for non-ST-elevation acute coronary syndrome: the Clopidogrel in Unstable angina to prevent Recurrent ischemic Events (CURE) Trial. Circulation. 2004;110: 1202-8.

119. Kim DH, Daskalakis C, Silvestry SC, et al. Aspirin and clopidogrel use in the early postoperative period following on-pump and off-pump coronary artery bypass grafting. J Thorac Cardiovasc Surg. 2009;138:1377-84.

120. Sørensen R, Abildstrøm SZ, Hansen PR, et al. Efficacy of post-operative clopidogrel treatment in patients revascularized with coronary artery bypass grafting after myocardial infarction. J Am Coll Cardiol. 2011;57:1202-9.

121. Gao G, Zheng Z, Pi Y, et al. Aspirin plus clopidogrel therapy increases early venous graft patency after coronary artery bypass surgery a single-center, randomized, controlled trial. J Am Coll Cardiol. 2010;56:1639-43.

122. Deo SV, Dunlay SM, Shah IK, et al. Dual anti-platelet therapy after coronary artery bypass grafting: is there any benefit? A systematic review and meta-analysis. J Card Surg. 2013;28:109-16.

123. Nocerino AG, Achenbach S, Taylor AJ. Meta-analysis of effect of single versus dual antiplatelet therapy on early patency of bypass conduits after coronary artery bypass grafting. Am J Cardiol. 2013;112:1576-9.

124. Ibrahim K, Tjomsland O, Halvorsen D, et al. Effect of clopidogrel on midterm graft patency following off-pump coronary revascularization surgery. Heart Surg Forum. 2006;9:E581-856.

125. Mannacio VA, Di Tommaso L, Antignan A, et al. Aspirin plus clopidogrel for optimal platelet inhibition following off-pump coronary artery bypass surgery: results from the CRYSSA (prevention of Coronary arteRY bypaSS occlusion After off-pump procedures) randomised study. Heart. 2012;98:1710-5.

126. Farooq V, Serruys PW, Bourantas C, et al. Incidence and multivariable correlates of long-term mortality in patients treated with surgical or percutaneous revascularization in the Synergy between Percutaneous Coronary Intervention with Taxus and Cardiac Surgery (SYNTAX) trial. Eur Heart J. 2012;33: 3105-13.

127. Johnson WD, Kayser KL, Hartz AJ, et al. Aspirin use and survival after coronary bypass surgery. Am Heart J. 1992;123:603-8.

128. Chesebro JH, Clements IP, Fuster V, et al. A platelet-inhibitor-drug trial in coronary-artery bypass operations: benefit of perioperative dipyridamole and aspirin therapy on early postoperative vein-graft patency. $N$ Engl J Med. 1982;307:73-8.

129. Chesebro JH, Fuster V, Elveback LR, et al. Effect of dipyridamole and aspirin on late vein-graft patency after coronary bypass operations. N Engl J Med. 1984; 310:209-14.

130. Goldman S, Copeland J, Moritz T, et al. Improvement in early saphenous vein graft patency after coronary artery bypass surgery with antiplatelet therapy: results of a Veterans Administration Cooperative Study. Circulation. 1988;77: 1324-32.

131. Ebrahimi R, Bakaeen FG, Uberoi A, et al. Effect of clopidogrel use post coronary artery bypass surgery on graft patency. Ann Thorac Surg. 2014;97:15-21.

132. Kulik A, Le May MR, Voisine P, et al. Aspirin plus clopidogrel versus aspirin alone after coronary artery bypass grafting: the Clopidogrel After Surgery for Coronary Artery Disease (CASCADE) Trial. Circulation. 2010;122:2680-7.

133. Gao C, Ren C, Li D, et al. Clopidogrel and aspirin versus clopidogrel alone on graft patency after coronary artery bypass grafting. Ann Thorac Surg. 2009;88: 59-62.

134. Sun JCJ, Teoh KHT, Lamy A, et al. Randomized trial of aspirin and clopidogrel versus aspirin alone for the prevention of coronary artery bypass graft occlusion: the Preoperative Aspirin and Postoperative Antiplatelets in Coronary Artery Bypass Grafting study. Am Heart J. 2010;160:1178-84. 
135. de Leon N, Jackevicius CA. Use of aspirin and clopidogrel after coronary artery bypass graft surgery. Ann Pharmacother. 2012;46:678-87.

136. Gurbuz AT, Zia AA, Vuran AC, et al. Postoperative clopidogrel improves midterm outcome after off-pump coronary artery bypass graft surgery: a prospective study. Eur J Cardiothorac Surg. 2006;29:190-5.

137. Smith PK, Goodnough LT, Levy JH, et al. Mortality benefit with prasugrel in the TRITON-TIMI 38 coronary artery bypass grafting cohort: risk-adjusted retrospective data analysis. J Am Coll Cardiol. 2012;60:388-96.

138. Held C, Asenblad N, Bassand JP, et al. Ticagrelor versus clopidogrel in patients with acute coronary syndromes undergoing coronary artery bypass surgery: results from the PLATO (Platelet Inhibition and Patient Outcomes) trial. J Am Coll Cardiol. 2011;57:672-84.

139. Varenhorst C, Alstrom U, Scirica BM, et al. Factors contributing to the lower mortality with ticagrelor compared with clopidogrel in patients undergoing coronary artery bypass surgery. J Am Coll Cardiol. 2012;60:1623-30.

140. Chen ZM, Jiang LX, Chen YP, et al. Addition of clopidogrel to aspirin in 45,852 patients with acute myocardial infarction: randomised placebo-controlled trial. Lancet. 2005;366:1607-21.

141. Roe MT, Armstrong PW, Fox KAA, et al. Prasugrel versus clopidogrel for acute coronary syndromes without revascularization. N Engl J Med. 2012;367: 1297-309.

142. Sabatine MS, Cannon CP, Gibson CM, et al. Addition of clopidogrel to aspirin and fibrinolytic therapy for myocardial infarction with ST-segment elevation. $N$ Engl J Med. 2005;352:1179-89.

143. Wijeysundera DN, Wijeysundera HC, Yun L, et al. Risk of elective major noncardiac surgery after coronary stent insertion: a population-based study. Circulation. 2012;126:1355-62.

144. Berger PB, Kleiman NS, Pencina MJ, et al. Frequency of major noncardiac surgery and subsequent adverse events in the year after drug-eluting stent placement results from the EVENT (Evaluation of Drug-Eluting Stents and Ischemic Events) Registry. JACC Cardiovasc Interv. 2010;3:920-7.

145. Mehran R, Baber U, Steg PG, et al. Cessation of dual antiplatelet treatment and cardiac events after percutaneous coronary intervention (PARIS): 2 year results from a prospective observational study. Lancet. 2013;382:1714-22.

146. Holcomb CN, Hollis RH, Graham LA, et al. Association of coronary stent indication with postoperative outcomes following noncardiac surgery. JAMA Surg. 2015;1-8.

147. Siller-Matula JM, Petre A, Delle-Karth G, et al. Impact of preoperative use of $\mathrm{P}_{2} \mathrm{Y}_{12}$ receptor inhibitors on clinical outcomes in cardiac and non-cardiac surgery: a systematic review and meta-analysis. Eur Heart J Acute Cardiovasc Care. 2015 [Epub ahead of print].

148. Chee YL, Crawford JC, Watson HG, et al. Guidelines on the assessment of bleeding risk prior to surgery or invasive procedures. British Committee for Standards in Haematology. Br J Haematol. 2008;140:496-504.

149. van Werkum JW, Heestermans AA, Zomer AC, et al. Predictors of coronary stent thrombosis: the Dutch Stent Thrombosis Registry. J Am Coll Cardiol. 2009;53:1399-409.

150. Secemsky EA, Matteau A, Yeh RW, et al. Comparison of short- and long-term cardiac mortality in early versus late stent thrombosis (from Pooled PROTECT Trials). Am J Cardiol. 2015;115:1678-84.

151. Holcomb CN, Graham LA, Richman JS, et al. The incremental risk of noncardiac surgery on adverse cardiac events following coronary stenting. J Am Coll Cardiol. 2014;64:2730-9.
152. Cruden NLM, Harding SA, Flapan AD, et al. Previous coronary stent implantation and cardiac events in patients undergoing noncardiac surgery. Circ Cardiovasc Interv. 2010;3:236-42.

153. Hawn MT, Graham LA, Richman JS, et al. Risk of major adverse cardiac events following noncardiac surgery in patients with coronary stents. JAMA. 2013;310: 1462-72.

154. Rajagopalan S, Ford I, Bachoo P, et al. Platelet activation, myocardial ischemic events and postoperative non-response to aspirin in patients undergoing major vascular surgery. J Thromb Haemost. 2007;5:2028-35.

155. Diamantis T, Tsiminikakis N, Skordylaki A, et al. Alterations of hemostasis after laparoscopic and open surgery. Hematology. 2007;12:561-70.

156. Fleisher LA, Beckman JA, Brown KA, et al. ACC/AHA 2007 guidelines on perioperative cardiovascular evaluation and care for noncardiac surgery: a report of the American College of Cardiology/American Heart Association Task Force on Practice Guidelines (Writing Committee to Revise the 2002 Guidelines on Perioperative Cardiovascular Evaluation for Noncardiac Surgery). Developed in collaboration with the American Society of Echocardiography, American Society of Nuclear Cardiology, Heart Rhythm Society, Society of Cardiovascular Anesthesiologists, Society for Cardiovascular Angiography and Interventions, Society for Vascular Medicine and Biology, and Society for Vascular Surgery. Circulation. 2007;116:e418-99.

157. Oscarsson A, Gupta A, Fredrikson M, et al. To continue or discontinue aspirin in the perioperative period: a randomized, controlled clinical trial. Br J Anaesth. 2010;104:305-12.

158. Burger W, Chemnitius J-M, Kneissl GD, et al. Low-dose aspirin for secondary cardiovascular prevention-cardiovascular risks after its perioperative withdrawal versus bleeding risks with its continuation-review and meta-analysis. J Intern Med. 2005;257:399-414.

159. Alshawabkeh LI, Prasad A, Lenkovsky F, et al. Outcomes of a preoperative "bridging" strategy with glycoprotein IIb/IIIa inhibitors to prevent perioperative stent thrombosis in patients with drug-eluting stents who undergo surgery necessitating interruption of thienopyridine administration. EuroIntervention. 2013;9:204-11.

160. Angiolillo DJ, Firstenberg MS, Price MJ, et al. Bridging antiplatelet therapy with cangrelor in patients undergoing cardiac surgery: a randomized controlled trial. JAMA. 2012;307:265-74.

161. Savonitto S, D’Urbano M, Caracciolo M, et al. Urgent surgery in patients with a recently implanted coronary drug-eluting stent: a phase II study of "bridging" antiplatelet therapy with tirofiban during temporary withdrawal of clopidogrel. Br J Anaesth. 2010;104:285-91.

162. Savonitto S, Caracciolo M, Cattaneo M, et al. Management of patients with recently implanted coronary stents on dual antiplatelet therapy who need to undergo major surgery. J Thromb Haemost. 2011;9:2133-42.

163. Warshauer J, Patel VG, Christopoulos G, et al. Outcomes of preoperative bridging therapy for patients undergoing surgery after coronary stent implantation: a weighted meta-analysis of 280 patients from eight studies. Catheter Cardiovasc Interv. 2015;85:25-31.

Key Words: AHA, Scientific Statements acute coronary syndrome, aspirin coronary artery disease coronary stents dual antiplatelet therapy (DAPT) focused update $\mathrm{P} \mathrm{Y}_{12}$ inhibitor stable ischemic heart disease 


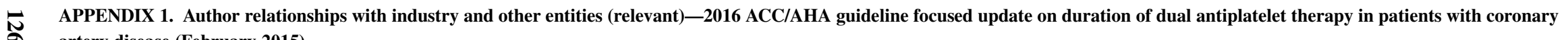

\begin{tabular}{|c|c|c|c|c|c|c|c|c|}
\hline Committee member & Employer/title & Consultant & $\begin{array}{c}\text { Speakers } \\
\text { bureau }\end{array}$ & $\begin{array}{c}\text { Ownership/ } \\
\text { partnership/ } \\
\text { principal }\end{array}$ & $\begin{array}{l}\text { Personal } \\
\text { research }\end{array}$ & $\begin{array}{l}\text { Institutional, } \\
\text { organizational, } \\
\text { or other } \\
\text { financial benefit }\end{array}$ & $\begin{array}{l}\text { Expert } \\
\text { witness }\end{array}$ & $\begin{array}{c}\text { Voting } \\
\text { recusals } \\
\text { by section* }\end{array}$ \\
\hline Glenn N. Levine, Chair & $\begin{array}{l}\text { Baylor College of Medicine- } \\
\text { Professor of Medicine; Director, } \\
\text { Cardiac Care Unit }\end{array}$ & None & None & None & None & None & None & None \\
\hline Eric R. Bates, Vice Chair, PCI & $\begin{array}{l}\text { University of Michigan—Professor of } \\
\text { Medicine }\end{array}$ & $\begin{array}{l}\text { - AstraZeneca } \\
\text { - Merck }\end{array}$ & None & None & None & None & None & All sections \\
\hline John A. Bittl & $\begin{array}{l}\text { Munroe Regional Medical Center- } \\
\text { Interventional Cardiologist }\end{array}$ & None & None & None & None & None & None & None \\
\hline Ralph G. Brindis & $\begin{array}{l}\text { University of California, San } \\
\text { Francisco-Philip R. Lee Institute } \\
\text { for Health Policy Studies- } \\
\text { Clinical Professor of Medicine }\end{array}$ & None & None & None & None & None & None & None \\
\hline Stephan D. Fihn, Chair, SIHD & $\begin{array}{l}\text { Department of Veterans Affairs- } \\
\text { Director, Office of Analytics and } \\
\text { Business Intelligence }\end{array}$ & None & None & None & None & None & None & None \\
\hline Lee A. Fleisher, Chair, Periop & $\begin{array}{l}\text { University of Pennsylvania, } \\
\text { Department of Anesthesiology- } \\
\text { Professor of Anesthesiology }\end{array}$ & None & None & None & None & None & None & None \\
\hline Christopher B. Granger & $\begin{array}{l}\text { Duke Clinical Research Institute- } \\
\text { Director, Cardiac Care Unit; } \\
\text { Professor of Medicine }\end{array}$ & $\begin{array}{l}\text { - AstraZeneca } \\
\text { - Bayer } \\
\text { - Bristol-Myers Squibb } \ddagger \\
\text { - Daiichi-Sankyo } \\
\text { - Janssen Pharmaceuticals } \\
\text { - Sanofi-Aventis } \\
\text { - Eli Lilly }\end{array}$ & None & None & $\begin{array}{l}\text { - AstraZeneca } \ddagger \\
\text { - Bayer } \ddagger \\
\text { - } \text { Bristol-Myers Squibb } \ddagger \\
\text { - } \text { Daiichi-Sankyo } \ddagger \\
\text { - Janssen Pharmaceuticals } \ddagger \\
\text { - Merck } \ddagger \\
\text { - Sanofi-Aventis } \ddagger\end{array}$ & None & None & All sections \\
\hline Richard A. Lange & $\begin{array}{l}\text { Texas Tech University Health } \\
\text { Sciences Center El Paso-- } \\
\text { President; Paul L. Foster School of } \\
\text { Medicine-Dean }\end{array}$ & None & None & None & None & None & None & None \\
\hline Michael J. Mack & The Heart Hospital Baylor-Director & None & None & None & - Abbott Vascular $\dagger$ & None & None & All sections \\
\hline Laura Mauri & $\begin{array}{l}\text { Brigham \& Women's Hospital- } \\
\text { Professor of Medicine, Harvard } \\
\text { Medical School }\end{array}$ & None & None & None & $\begin{array}{l}\text { - Abbott } \ddagger \\
\text { - Bristol-Myers Squibb } \ddagger \\
\text { - Daiichi-Sankyo } \ddagger \\
\text { - Eli Lilly } \ddagger \\
\text { - Sanofi-Aventis } \ddagger\end{array}$ & None & None & All sections \\
\hline Roxana Mehran & $\begin{array}{l}\text { Mount Sinai Medical Center- } \\
\text { Professor of Medicine }\end{array}$ & $\begin{array}{l}\text { - Abbott } \\
\text { - AstraZeneca } \\
\text { - Merck }\end{array}$ & None & None & $\begin{array}{l}\text { - AstraZeneca } \ddagger \\
\text { - Lilly/DSI } \dagger \\
\text { - STENTYS } \dagger\end{array}$ & None & None & All sections \\
\hline
\end{tabular}




\section{Committee member}

Employer/title

Consultant

research

bureau

principal

Institutional,

organizational,

or other

Expert recusals

Debabrata Mukherjee

Texas Tech University—Chief,

None

Cardiovascular Medicine

L. Kristin Newby

Duke University Medical Center,

- Janssen Pharmaceuticals $\ddagger \quad$ None

None

financial bene

ness by section*

Division of Cardiology—Professor • Merck

of Medicine

है

Harvard Medical School—Professor

None

None

None

- Bristol-Myers Squibb

- AstraZeneca $\dagger$ None All sections

of Medicine

Brigham and Women's Hospital,

Chairman-TIMI Study Group,

- AstraZeneca

- Merck

Division of Cardiovascular

- Sanofi-Aventis

Medicine; Harvard Medical

School—Professor of Medicine

Peter K. Smith, Vice Chair, CABG Duke University Medical Center-

Professor of Surgery; Chief,

Thoracic Surgery

Sidney C. Smith, Jr University of North Carolina-

Professor of Medicine; Center for

Cardiovascular Science and

Medicine-Director

This table represents the relationships of committee members with industry and other entities that were determined to be relevant to this document. These relationships were reviewed and updated in conjunction with all meetings and/ or conference calls of the writing committee during the document development process. The table does not necessarily reflect relationships with industry at the time of publication. A person is deemed to have a significant interest in a business if the interest represents ownership of $\geq 5 \%$ of the voting stock or share of the business entity, or ownership of $\geq \$ 5000$ of the fair market value of the business entity, or if funds received by the person from the business entity exceed $5 \%$ of the person's gross income for the previous year. Relationships that exist with no financial benefit are also included for the purpose of transparency. Relationships in this table are modest unless otherwise noted. According to the ACC/AHA, a person has a relevant relationship IF: a) the relationship or interest relates to the same or similar subject matter, intellectual property or asset, topic, or issue addressed in the document; or b) the company/entity (with whom the relationsip exists) makes a drug, drug class, or device addressed in the document, or makes a competing drug or device addressed in the document; or c) the person or a member of the person's household has a reasonable noncardiac surgery; STEMI, ST-elevation myocardial infarction; TIMI, Thrombosis In Myocardial Infarction; CABG, coronary artery bypass graft surgery. *Writing committee members are required to recuse themselves from voting on sections to which their specific relationships with industry and other entities may apply. †No financial benefit. †Significant relationship. 


\begin{tabular}{|c|c|c|c|c|c|c|c|c|}
\hline Reviewer & Representation & Employment & Consultant & $\begin{array}{c}\text { Speakers } \\
\text { bureau }\end{array}$ & $\begin{array}{c}\text { Ownership/ } \\
\text { partnership/ } \\
\text { principal }\end{array}$ & $\begin{array}{l}\text { Personal } \\
\text { research }\end{array}$ & $\begin{array}{c}\text { organizational, } \\
\text { or other } \\
\text { financial benefit }\end{array}$ & $\begin{array}{l}\text { Expert } \\
\text { witness }\end{array}$ \\
\hline Joseph S. Alpert & Official Reviewer-AHA & $\begin{array}{l}\text { University of Arizona } \\
\text { Health Sciences } \\
\text { Center-Professor of } \\
\text { Medicine, Head of } \\
\text { Department of } \\
\text { Medicine }\end{array}$ & $\begin{array}{l}\text { - AstraZeneca } \\
\text { - Bayer } \\
\text { - Daiichi-Sankyo } \\
\text { - Sanofi-Aventis } \\
\text { - Servier } \\
\text { Pharmaceuticals } \\
\text { - ZS Pharma }\end{array}$ & None & None & $\begin{array}{l}\text { - } \text { Bayer Pharma } \\
\text { (DSMB) } \dagger \\
\text { - Janssen } \\
\text { Pharmaceuticals } \\
\text { (DSMB) } \\
\text { - ZS Pharma* }\end{array}$ & None & None \\
\hline Joaquin E. Cigarroa & $\begin{array}{l}\text { Official Reviewer-ACC/ } \\
\text { AHA Task Force on } \\
\text { Clinical Practice } \\
\text { Guidelines }\end{array}$ & $\begin{array}{l}\text { Oregon Health and } \\
\text { Science University- } \\
\text { Clinical Professor of } \\
\text { Medicine }\end{array}$ & None & None & None & None & None & None \\
\hline Ian C. Gilchrist & Official Reviewer-AHA & $\begin{array}{l}\text { Hershey Medical } \\
\text { Center-Physician, } \\
\text { Professor of Medicine }\end{array}$ & $\begin{array}{l}\text { - Terumo Interventional } \\
\text { Systems }\end{array}$ & None & None & $\begin{array}{l}\text { - Angel Medical } \\
\text { Systems } \dagger \\
\text { - Eli Lilly }\end{array}$ & None & None \\
\hline Dipti Itchhaporia & $\begin{array}{l}\text { Official Reviewer-ACC } \\
\text { Board of Trustees }\end{array}$ & $\begin{array}{l}\text { Newport Coast } \\
\text { Cardiology-Robert } \\
\text { and Georgia Roth Chair } \\
\text { of Cardiac Excellence; } \\
\text { Hoag Heart and } \\
\text { Vascular Institute- } \\
\text { Medical Director, } \\
\text { Disease Management }\end{array}$ & None & None & None & None & None & None \\
\hline Mladen I. Vidovich & $\begin{array}{c}\text { Official Reviewer-ACC } \\
\text { Board of Governors }\end{array}$ & $\begin{array}{l}\text { University of Illinois- } \\
\text { Associate Professor of } \\
\text { Medicine; Jesse Brown } \\
\text { VA Medical Center- } \\
\text { Chief of Cardiology }\end{array}$ & None & $\begin{array}{l}\bullet \text { Eli Lilly/ } \\
\text { Daiichi- Sankyo* }\end{array}$ & None & None & None & None \\
\hline Dawn J. Abbott & $\begin{array}{l}\text { Organizational } \\
\quad \text { Reviewer-SCAI }\end{array}$ & $\begin{array}{l}\text { Brown University- } \\
\text { Director of } \\
\text { Interventional } \\
\text { Cardiology Fellowship } \\
\text { Training Program }\end{array}$ & None & None & None & None & - AstraZeneca $\dagger$ & None \\
\hline Dominick J. Angiolillo & $\begin{array}{l}\text { Organizational } \\
\quad \text { Reviewer-SCAI }\end{array}$ & $\begin{array}{l}\text { University of Florida } \\
\text { College of Medicine- } \\
\text { Cardiovascular } \\
\text { Research Director }\end{array}$ & $\begin{array}{l}\text { - Abbott Vascular } \\
\text { - PLx Pharma } \\
\text { - Sanofi-Aventis* } \\
\text { - Eli Lilly* } \\
\text { - Daiichi-Sankyo* }\end{array}$ & None & None & $\begin{array}{l}\text { - Eli Lilly* } \\
\text { - Daiichi-Sankyo* } \\
\text { - AstraZeneca } \\
\text { - Janssen* } \\
\text { Pharmaceuticals* }\end{array}$ & None & None \\
\hline
\end{tabular}




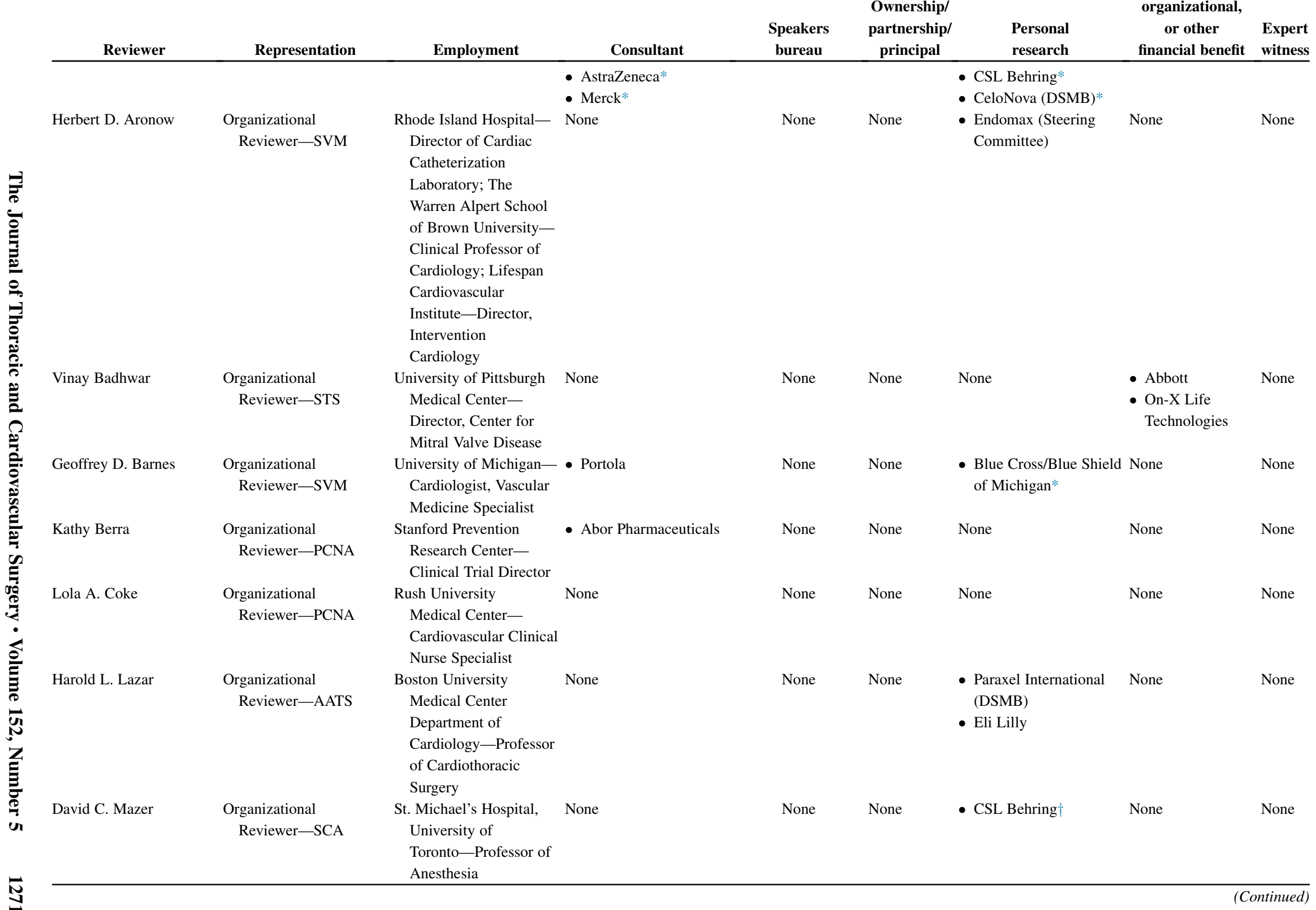




\begin{tabular}{|c|c|c|c|c|c|c|c|c|}
\hline Reviewer & Representation & Employment & Consultant & $\begin{array}{c}\text { Speakers } \\
\text { bureau }\end{array}$ & $\begin{array}{c}\text { Ownership/ } \\
\text { partnership/ } \\
\text { principal }\end{array}$ & $\begin{array}{l}\text { Personal } \\
\text { research }\end{array}$ & $\begin{array}{c}\text { Institutional, } \\
\text { organizational, } \\
\text { or other } \\
\text { financial benefit }\end{array}$ & $\begin{array}{l}\text { Expert } \\
\text { witness }\end{array}$ \\
\hline John D. Puskas & $\begin{array}{l}\text { Organizational } \\
\text { Reviewer-AATS }\end{array}$ & $\begin{array}{l}\text { Icahn School of Medicine } \\
\text { at Mount Sinai, Emory } \\
\text { Crawford Long } \\
\text { Hospital—Chief of } \\
\text { Cardiac Surgery }\end{array}$ & None & None & None & None & None & None \\
\hline Joseph F. Sabik & $\begin{array}{l}\text { Organizational } \\
\text { Reviewer-STS }\end{array}$ & $\begin{array}{l}\text { Cleveland Clinic, } \\
\text { Department of Thoracic } \\
\text { and Cardiovascular } \\
\text { Surgery-Department } \\
\text { Chair }\end{array}$ & - Medistem & None & None & - Abbott $\dagger$ & None & None \\
\hline Linda Shore-Lesserson & $\begin{array}{l}\text { Organizational } \\
\text { Reviewer-ASA/SCA }\end{array}$ & $\begin{array}{l}\text { Hofstra Northwell School } \\
\text { of Medicine-Director, } \\
\text { Cardiovascular } \\
\text { Anesthesiology }\end{array}$ & $\begin{array}{l}\text { - Elcam Medical } \\
\text { - Grifols }\end{array}$ & None & None & None & None & None \\
\hline Scott M. Silvers & $\begin{array}{l}\text { Organizational } \\
\text { Reviewer-ACEP }\end{array}$ & $\begin{array}{l}\text { Mayo Clinic College of } \\
\text { Medicine, Emergency } \\
\text { Medicine-Chair and } \\
\text { Associate Professor }\end{array}$ & None & None & None & None & None & None \\
\hline Christian A. Tomaszewski & $\begin{array}{l}\text { Organizational } \\
\text { Reviewer-ACEP }\end{array}$ & $\begin{array}{l}\text { University of California } \\
\text { San Diego Health- } \\
\text { Emergency Medicine, } \\
\text { Medical Toxicology } \\
\text { Specialist }\end{array}$ & None & None & None & None & None & None \\
\hline Sana M. Al-Khatib & $\begin{array}{l}\text { Content Reviewer-ACC/ } \\
\text { AHA Task Force on } \\
\text { Clinical Practice } \\
\text { Guidelines }\end{array}$ & $\begin{array}{l}\text { Duke University Medical } \\
\text { Center-Associate } \\
\text { Professor of Medicine }\end{array}$ & None & None & None & None & None & None \\
\hline Saif Anwaruddin & $\begin{array}{l}\text { Content Reviewer-ACC } \\
\text { Interventional } \\
\text { Scientific Council }\end{array}$ & $\begin{array}{l}\text { University of } \\
\text { Pennsylvania- } \\
\text { Transcatheter Valve } \\
\text { Program Co-Director, } \\
\text { Assistant Professor of } \\
\text { Medicine }\end{array}$ & None & None & None & None & None & None \\
\hline Deepak L. Bhatt & Content Reviewer & $\begin{array}{l}\text { Brigham and Women's } \\
\text { Hospital—Executive } \\
\text { Director of } \\
\text { Interventional } \\
\text { Cardiovascular }\end{array}$ & None & None & None & $\begin{array}{l}\text { - Amarin* } \\
\text { - AstraZeneca* } \\
\text { - Bristol-Myers Squibb* } \\
\text { - Cardax } \dagger \\
\text { - Elsai* }\end{array}$ & None & None \\
\hline
\end{tabular}




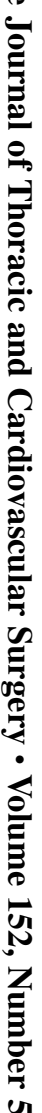

Kim K. Birtcher

Content Reviewer-ACC/ University of Houston None

AHA Task Force on College of Pharmacy-

Clinical Practice Clinical Professor

Guidelines

Biykem Bozkurt Content Reviewer-ACC/ Michael E. DeBakey VA None

AHA Task Force on Medical Center-The

Clinical Practice Mary and Gordon Cain

Guidelines Chair and Professor of Medicine

Michael A. Borger Content Reviewer-ACC Columbia University None

Surgeons' Scientific Medical Center-

Division of Cardiac,

Vascular and Thoracic

Surgery, Cardiothoracic Surgeon

Mauricio G. Cohen Content Reviewer University of Miami

School of Medicine-

- Terumo Medical

None

None

- AstraZeneca

None

None

Director of Cardiac

Catheterization

Laboratory

Frederico Gentile Content Reviewer-ACC/ Centro Medico Non

AHA Task Force on Diagnostico-Director,

Clinical Practice Cardiovascular Disease

Guidelines

Samuel S. Gidding

Content Reviewer-ACC/ Nemours/Alfred I.

None

AHA Task Force on DuPont Hospital for

Clinical Practice Children-Chief,

Guidelines

Division of Pediatric

Cardiology

Alan L. Hinderliter

Content Reviewer

None

None

None

None

None

None

N 


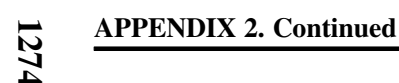

\begin{tabular}{|c|c|c|c|c|c|c|c|c|}
\hline Reviewer & Representation & Employment & Consultant & $\begin{array}{c}\text { Speakers } \\
\text { bureau }\end{array}$ & $\begin{array}{c}\text { Ownership/ } \\
\text { partnership/ } \\
\text { principal }\end{array}$ & $\begin{array}{l}\text { Personal } \\
\text { research }\end{array}$ & $\begin{array}{c}\text { Institutional, } \\
\text { organizational, } \\
\text { or other } \\
\text { financial benefit }\end{array}$ & $\begin{array}{l}\text { Expert } \\
\text { witness }\end{array}$ \\
\hline & & $\begin{array}{l}\text { University of North } \\
\text { Carolina-Division of } \\
\text { Cardiology }\end{array}$ & & & & & & \\
\hline David R. Holmes & $\begin{array}{l}\text { Content Reviewer-ACC } \\
\text { Surgeons' Scientific } \\
\text { Council }\end{array}$ & $\begin{array}{l}\text { Mayo Clinic- } \\
\text { Consultant, } \\
\text { Cardiovascular Disease }\end{array}$ & None & None & None & None & None & None \\
\hline José A. Joglar & $\begin{array}{l}\text { Content Reviewer-ACC/ } \\
\text { AHA Task Force on } \\
\text { Clinical Practice } \\
\text { Guidelines }\end{array}$ & $\begin{array}{l}\text { University of Texas } \\
\text { Southwestern Medical } \\
\text { Center-Professor of } \\
\text { Internal Medicine }\end{array}$ & None & None & None & None & None & None \\
\hline Ajay J. Kirtane & Content Reviewer & $\begin{array}{l}\text { Columbia University } \\
\text { Medical Center- } \\
\text { Associate Professor of } \\
\text { Medicine; Center for } \\
\text { Interventional Vascular } \\
\text { Therapy-Chief } \\
\text { Academic Officer; } \\
\text { NYC/Columbia } \\
\text { Cardiac Catheterization } \\
\text { Laboratories-Director }\end{array}$ & None & None & None & $\begin{array}{l}\text { - Abbott Vascular* } \\
\text { - Eli Lilly* }\end{array}$ & $\begin{array}{l}\text { - Abbott Vascular* } \\
\text { - Eli Lilly* }\end{array}$ & None \\
\hline Lloyd W. Klein & $\begin{array}{l}\text { Content Reviewer-ACC } \\
\text { Interventional } \\
\text { Scientific Council }\end{array}$ & $\begin{array}{l}\text { Rush Medical College- } \\
\text { Professor of Medicine }\end{array}$ & None & None & None & None & None & None \\
\hline David J. Maron & Content Reviewer & $\begin{array}{l}\text { Stanford University } \\
\text { School of Medicine- } \\
\text { Clinical Professor of } \\
\text { Medicine and } \\
\text { Emergency Medicine }\end{array}$ & None & None & None & None & None & None \\
\hline Gilles Montalescot & Content Reviewer & $\begin{array}{l}\text { Pitie-Salpetriere } \\
\text { University Hospital- } \\
\text { Head of Institute of } \\
\text { Cardiology }\end{array}$ & $\begin{array}{l}\text { - Acuitude } \\
\text { - AstraZeneca } \\
\text { - Bayer } \\
\text { - Bristol-Myers Squibb } \\
\text { - Daiichi-Sankyo } \\
\text { - Eli Lilly } \\
\text { - Lead-up } \\
\text { - Medcon International } \\
\text { - Menarini } \\
\text { - MSD }\end{array}$ & None & None & $\begin{array}{l}\text { - AstraZeneca* } \\
\text { - Bristol-Myers Squibb* } \\
\text { - Celladon } \\
\text { - Daiichi-Sankyo* } \\
\text { - Eli Lilly* } \\
\text { - Janseen-CilagRecor } \\
\text { - Sanofi-Aventis } \\
\text { - Stentys* }\end{array}$ & None & None \\
\hline
\end{tabular}


Reviewer

Representation

Employment

sultant

- Stentys

Mark A. Munger

Content Reviewer

University of Utah-

\section{None}

Professor of Pharmacy

Practice

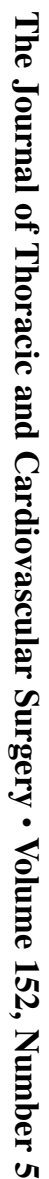

E. Magnus Ohman

Content Reviewer

Duke University-

- AstraZeneca

Professor of Medicine, - Janssen

Director of Program for Pharmaceuticals

Advanced Coronary

Disease

Eric R. Powers Content Reviewer

Medical U

South Carolina-

None

Service Line Medica

Director

Content Reviewer-ACC/ Indiana School of None

AHA Task Force on Nursing-Professor

Clinical Practice and Sally Reahard

Guidelines

Enhancing Quality of

Life in Chronic

Illness-Director

Sunil V. Rao Content Reviewer Duke University Medical None

Center-Associate

Professor of Medicine

Philippe Gabriel Steg Content Reviewer Université Paris-

Diderot—Professor

- AstraZeneca

- Bristol-Myers Squibb

- Daiichi-Sankyo

- Eli Lilly

- Merck

Tracy Y. Wang Content Reviewer

Duke University Medical • AstraZeneca

- Eli Lilly

Center-Associate

Professor of Medicine
None

None

- Janssen

Pharmaceuticals*

None

None

None

None

None

None

None

None

None

None

- AstraZeneca* None

None

- Bristol-Myers Squibb

- Eli Lilly/Daiichi-

Sankyo Alliance

This table represents the relationships of reviewers with industry and other entities that were disclosed at the time of peer review and determined to be relevant to this document. It does not necessarily reflect relationships with industry

at the time of publication. A person is deemed to have a significant interest in a business if the interest represents ownership of $\geq 5 \%$ of the voting stock or share of the business entity, or ownership of $\geq \$ 5000$ of the fair market value of the business entity, or if funds received by the person from the business entity exceed $5 \%$ of the person's gross income for the previous year. A relationship is considered to be modest if it is less than significant under the preceding definition. Relationships that exist with no financial benefit are also included for the purpose of transparency. Relationships in this table are modest unless otherwise noted. Names are listed in alphabetical order within each category of review. According to the ACC/AHA, a person has a relevant relationship IF: a) the relationship or interest relates to the same or similar subject matter, intellectual property or asset, topic, or issue addressed in the document; or b) the company/entity (with whom the relationship exists) makes a drug, drug class, or device addressed in the document, or makes a competing drug or device addressed in the document; or c) the person or a member of the person's

- household has a reasonable potential for financial, professional or other personal gain or loss as a result of the issues/content addressed in the document. AHA, American Heart Association; DSMB, data safety monitoring board;

I ACC, American College of Cardiology; SCAI, Society for Cardiovascular Angiography and Interventions; SVM, Society for Vascular Medicine; STS, Society of Thoracic Surgeons; PCNA, Preventive Cardiovascular Nurses Association; $A A T S$, American Association for Thoracic Surgery; SCA, Society of Cardiovascular Anesthesiologist; CSL, Coordinated Science Laboratory; ACEP, American College of Emergency Physicians. *Significant relationship. †No financial benefit. 